\title{
Ultrasensitive fluorescence-based methods for nucleic acid detection: towards amplification-free genetic analysis
}

\author{
Rohan T. Ranasinghe ${ }^{* a}$ and Tom Brown $* b$ \\ Received 4th October 2010, Accepted 5th January 2011 \\ DOI: $10.1039 / \mathrm{c0cc04215c}$
}

Real time PCR is the mainstay of current nucleic acid assays, underpinning applications in forensic science, point-of-care diagnostics and detection of bioterrorism agents. Despite its broad utility, the search for new tests continues, inspired by second and third generation DNA sequencing technologies and fuelled by progress in single molecule fluorescence spectroscopy, nanotechnology and microfabrication. These new methods promise the direct detection of nucleic acids without the need for enzymatic amplification. In this feature article, we provide a chemist's perspective on this multidisciplinary area, introducing the concepts of single molecule detection then focussing on the selection of labels and probe chemistry suitable for generating a signal detectable by ultrasensitive fluorescence spectroscopy. Finally, we discuss the further developments that are required to incorporate these detection platforms into integrated 'sample-in-answer-out' instruments, capable of detecting many target sequences in a matter of minutes.

\section{Introduction}

The impact of the polymerase chain reaction (PCR) on the fields of molecular biology, DNA sequencing, mRNA expression studies, genetic analysis, molecular diagnostics and forensic science has been revolutionary. The ability to amplify nucleic acid sequences of interest exponentially prior to their analysis has been central to countless applications in the last quarter of a century. ${ }^{1}$ At the same time, the advent of analytical techniques with extremely low limits of detection (down to single molecules) and lab-on-a-chip devices has led to technologies that do not require amplification of nucleic acids. ${ }^{2}$ Progress has been most dramatic in the field of DNA sequencing, where the drive toward the $\$ 1000$ genome has

${ }^{a}$ Department of Chemistry, University of Cambridge, Lensfield Road, Cambridge,UKCB2 1EW.E-mail: rr360@cam.ac.uk

${ }^{b}$ School of Chemistry, University of Southampton, Highfield,

Southampton, UK SO171BJ.E-mail:tb2@soton.ac.uk accelerated the development of second and third generation platforms that generate sequence data in a massively parallel manner from a few or even individual DNA molecules. Commercial platforms have been developed by Roche 454 Life Sciences, Illumina, Applied Biosystems, Helicos Biosciences and Pacific Biosciences among others. Some of the core design principles that are central to the material covered in this feature are nicely illustrated in a couple of examples from this rapidly evolving field.

In Illumina's sequencing-by-synthesis method, clonal arrays of $\sim 1000$ copies of the molecule to be sequenced are constructed on the surface of an optically transparent flow cell by polymerase amplification. ${ }^{3}$ Sequence information is then generated by extension of a primer using reversible dye terminator chemistry with four fluorescent dNTPs each labelled with a different colour (Fig. 1A). The $3^{\prime}$-oxygen of the fluorescent dNTP is blocked from further extension by the presence of an azidomethyl group. Unincorporated dNTPs are

Rohan T. Ranasinghe received his MChem (2000) and PhD (2005) from the University of Southampton under the supervision of Professor Tom Brown. From 2005-2008, he worked with Peter Roach in Southampton, synthesising oligonucleotides on encoded microparticles for use in multiplexed assays. Since 2008 he has been carrying out postdoctoral research with Professor David Klenerman at the University of Cambridge, with the aim of developing ultrasensitive point-of-care nucleic acid tests for infectious agents, as part of the European Commission-funded TheraEDGE project. His research interests include nucleic acids chemistry and biophysics, molecular diagnostics, single molecule fluorescence spectroscopy and synthesis of modified oligonucleotides.

Tom Brown received his first degree and PhD at Bradford University after which he moved to Nottingham University, then to Oxford and Cambridge Universities to carry out postdoctoral research. He was then appointed to a lectureship at Edinburgh University where he was promoted to Reader then Professor of Nucleic Acids Chemistry. He moved to a Chair in Chemistry at Southampton University in 1995. His research interests centre on Nucleic acids chemistry, structure, DNA sequence recognition and the application of oligonucleotide chemistry to biology and medicine. He is co-founder of three Biotech companies. 
A

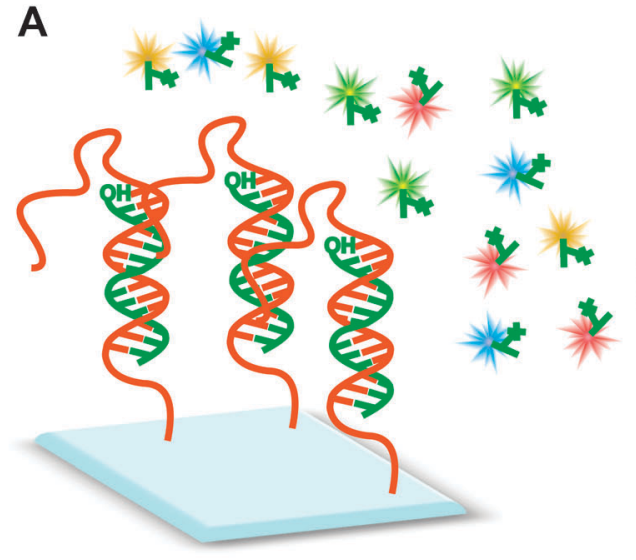

Dye-labelled dNTPs with removable 3'-blocking group

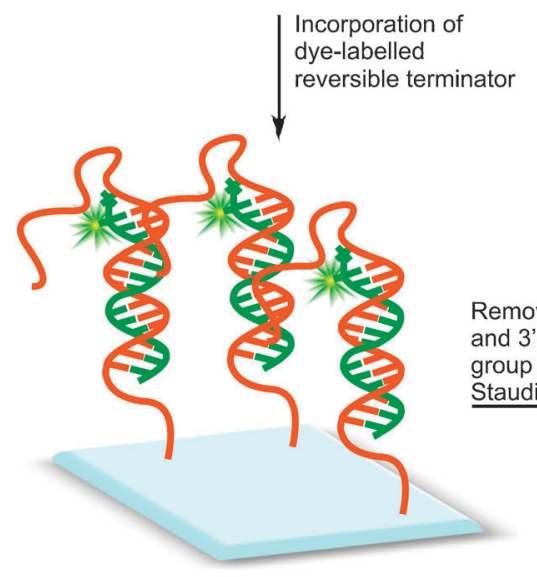

Identity of incorporated base established by fluorescence imaging
B<smiles>CCCCC(=O)NCCNC(=O)c1cccc(OCC(N)OCCOCC(=O)NCC#Cc2cn(C3COCCO3)c(=O)[nH]c2=O)c1</smiles>

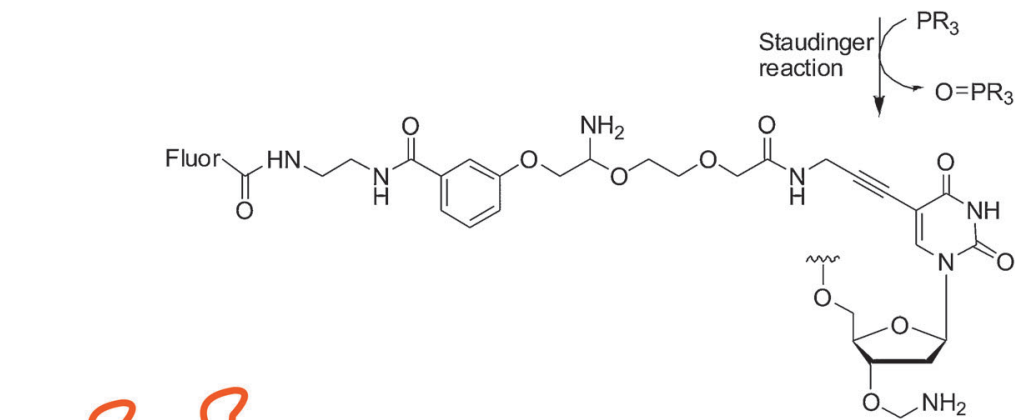
Staudinger/ $\mathrm{PR}_{3}$ reaction $\mathrm{O}=\mathrm{PR}_{3}$

Removal of dye and 3'-blocking group by taudinger Reaction
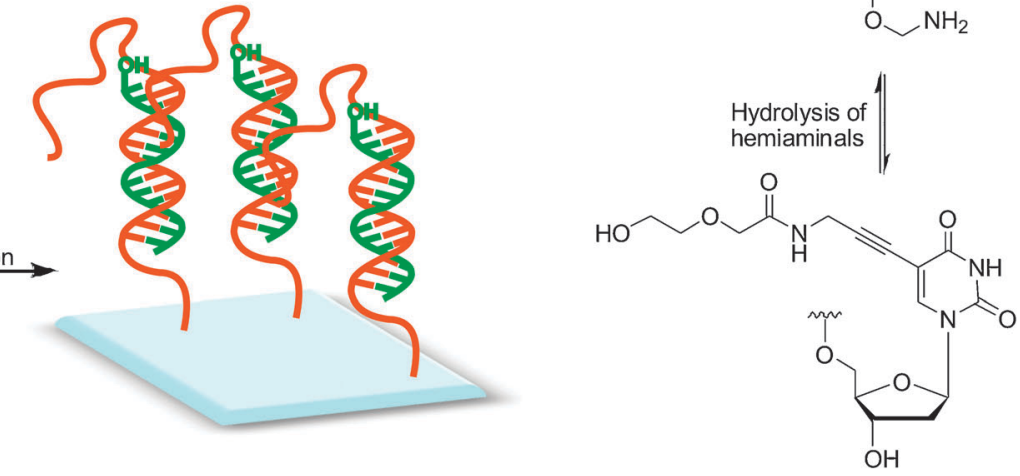

Non-fluorescent primers ready for next round of dNTP incorporation

Fig. 1 (A) Key steps in sequencing-by-synthesis using dye-labelled reversible terminators. (B) Chemical reactions occurring in the cleavage of dye molecule and $3^{\prime}$-blocking group.

then washed out of the flow cell and the identity of the attached nucleotide established by imaging using total internal reflection fluorescence microscopy (TIRFM) before cleavage of the fluorophore and $3^{\prime}$-protecting group. This is achieved using a Staudinger reaction between a water soluble phosphine and the azides, unmasking two hemiaminals which are rapidly hydrolysed (Fig. 1B). The released $3^{\prime}-\mathrm{OH}$ is then available for reaction in another round of single base extension.

Pacific Biosciences' single molecule real time (SMRT) sequencing method takes a more direct approach. ${ }^{4}$ Here, the processive incorporation of nucleotides by an individual polymerase is monitored (Fig. 2A). The fluorescent label is attached to the $\varepsilon$-phosphorus atom of a modified 2 -deoxynucleotide pentaphosphate (dN5P) and is thus ejected with the leaving group in the extension reaction (Fig. 2C). While this takes place, the dye is held in close proximity to the polymerase for a few hundred milliseconds, generating a 'pulse' of colour specific to each base (Fig. 2B). The product is an unmodified DNA strand which can continue to participate in polymerisation. Since the $K_{\mathrm{M}}$ of the DNA polymerase is in the $\mu \mathrm{M}$ range, tremendous spatial resolution is required to ensure that only triphosphates undergoing reaction give rise to signal. This is achieved by the use of nanofabricated zero-mode waveguide (ZMW) structures which can illuminate an incredibly small volume of 10-20 zeptolitres $\left(10-20 \times 10^{-21} \mathrm{~L}\right) .^{5}$

The science underlying these innovations is truly multidisciplinary; chemically modified nucleotides/nucleic acids for signal generation are combined with fluidic technology and sophisticated fluorescence detection methods. However, the detailed information generated by sequencing is unnecessary for small scale SNP analysis or pathogen detection. Fluorescence-based real time PCR has been the method of choice for these applications in recent years, which we reviewed five years ago. ${ }^{6}$ These assays typically rely on a fluorogenic oligonucleotide for recognition of a sequence of interest in the amplicon. Real time PCR is now widely used for nucleic acid-based diagnostics, and instruments for automated preparation of assay-ready samples (e.g. QIAsymphony by Qiagen), or for integrated sample processing, amplification and fluorescence measurement (e.g. the GeneXpert by Cepheid) have been marketed to meet the clinical need for 'sample-in-answer-out' capability. However, just as the Sanger method has evolved into second and third generation sequencing technologies, there has been a move towards sequence analysis platforms that rely on ultrasensitive 

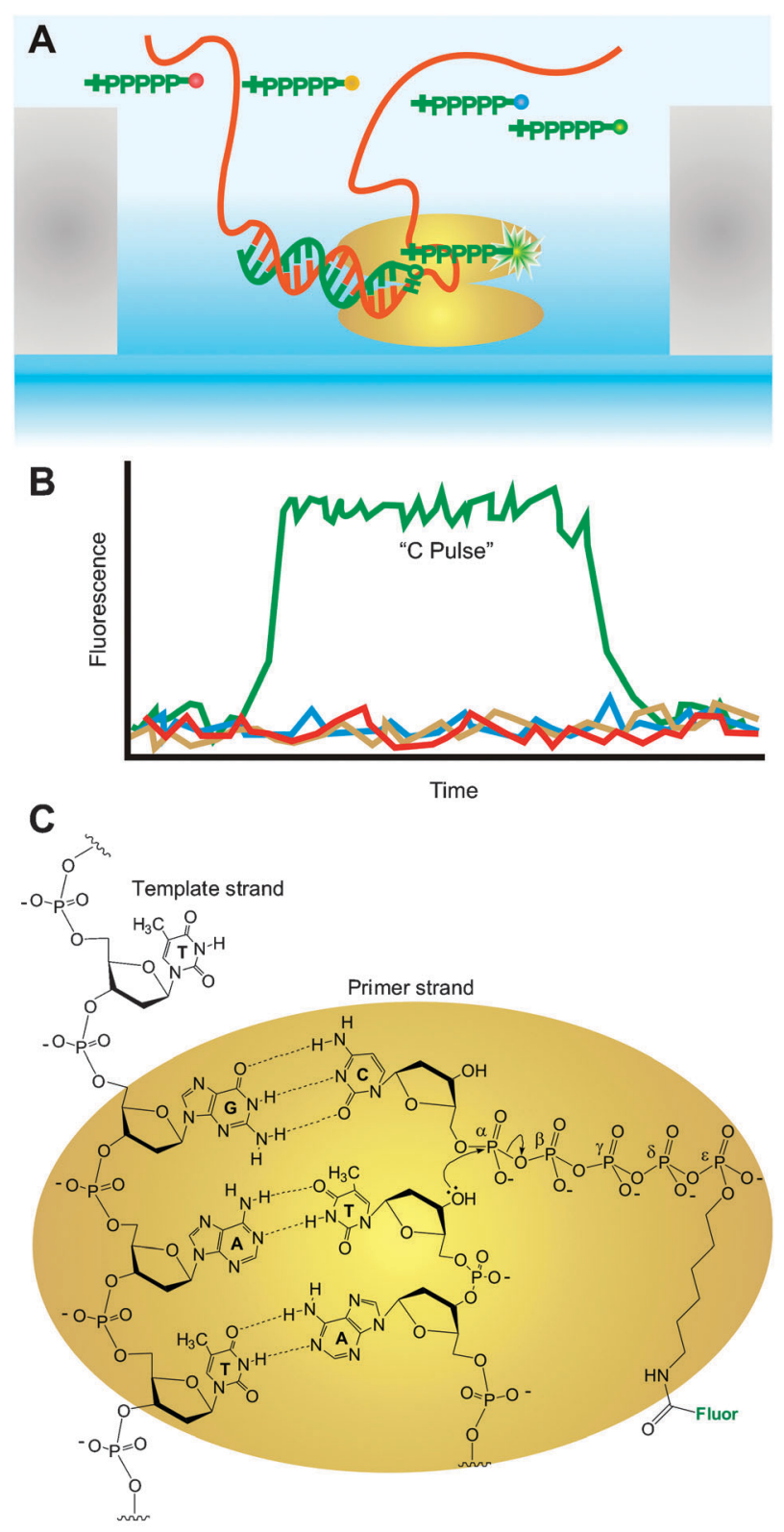

Fig. 2 Single molecule real time sequencing. (A) Extension of a primer by a single polymerase immobilised within a zero-mode waveguide (ZMW). (B) Fluorescence trace observed during extension. (C) Chemical mechanism of polymerisation reaction using fluorescently-labelled 2'-deoxynucleotide pentaphosphate (dN5P).

detection for the development of rapid assays that do not require PCR amplification of the target DNA. ${ }^{2}$

In this feature article, we discuss the progress that has been made toward developing this next generation of fluorescence-based genetic analysis technologies. We outline the principles of single molecule detection, discuss appropriate labelling chemistry for these applications and illustrate examples of assays that are being developed for use in this context. We have concentrated solely on methods that generate fluorescence readout, although much progress has been made in colourimetric, electrochemical and electronic detection. The reader is directed to other reviews covering these areas. ${ }^{7-9}$

\section{Single molecule fluorescence spectroscopy (SMFS)}

SMFS has become an established biophysical technique since its first demonstration nearly 35 years ago. ${ }^{10}$ The measurement of single fluorophores is now a routine practice in many laboratories as a result of technological advances, particularly in the 20 years since the first observation of single Rhodamine $6 \mathrm{G}$ molecules dissolved in water at room temperature. ${ }^{11}$ Commercial instruments, such as the MicroTime 200 by PicoQuant, have become available, underlining the maturity of the technology. The detailed technical development of SMFS and its application to studying biological questions have been reviewed extensively by leading practitioners in the field. ${ }^{12-18}$ As a result, this section is intended only to illustrate the basic principles underlying the analytical applications described in this article.

In order for single molecule detection (SMD) to be achieved, several conditions must be met. To maximise the signal, the detector must be very sensitive-typically, avalanche photodiodes (APDs), or charge-coupled device (CCD) cameras are used, and emitted photons must be collected very efficiently, usually by microscope objectives with very high numerical aperture (NA). The minimisation of background noise resulting from fluorescent impurities or Raman scattering from solvent molecules or bulk solutes is also of critical importance. This goal can be achieved by reducing the observation volume, since signals from bulk species increase with the volume sampled, while those from the single fluorophore of interest do not. There are three strategies for minimising the observation volume of particular interest for analytical applications: confocal illumination, total internal reflection microscopy (TIRFM) and the use of zeromode waveguides (ZMWs), each of which are described below. Finally, if analytes are moving, either by Brownian motion or in flowing samples, it is necessary to collect data in a timegated fashion, so that signals from individual molecules appear as discrete 'bursts' of fluorescence.

In the confocal setup (Fig. 3A), excitation light from a laser source is focussed by a microscope objective to a diffraction limited spot with a diameter of $\leq 1 \mu \mathrm{m},{ }^{19}$ whose radial intensity profile obeys a Gaussian function. Emitted photons are collected by the same objective, separated from excitation light by a dichroic mirror, and a pinhole (typically $50 \mu \mathrm{m}$ in width) is positioned in the conjugate image plane to reject outof-focus light. This arrangement of optical components defines an elliptical observation volume of $\sim 0.5 \mathrm{fL}$ (Fig. 3B). Even when sampling this minute volume, it is necessary to work at low concentrations of analytes to ensure observation of one molecule at a time. A simple calculation tells us that a concentration of $3.3 \mathrm{nM}$ would lead to an average of one molecule occupying this detection volume at a given time, and to ensure that discrete bursts from single molecules are observed, it is necessary to work at analyte concentrations of $10-100 \mathrm{pM}^{20}$ In this single molecule regime, it is possible to obtain multiple parameters such as fluorescence intensities, lifetimes, anisotropy and Förster resonance energy transfer (FRET) efficiency, ${ }^{21}$ though intensity and FRET are perhaps the most useful for molecular diagnostics.

In contrast to discrete burst analysis, fluorescence correlation spectroscopy (FCS) relies on measuring the temporal 
A
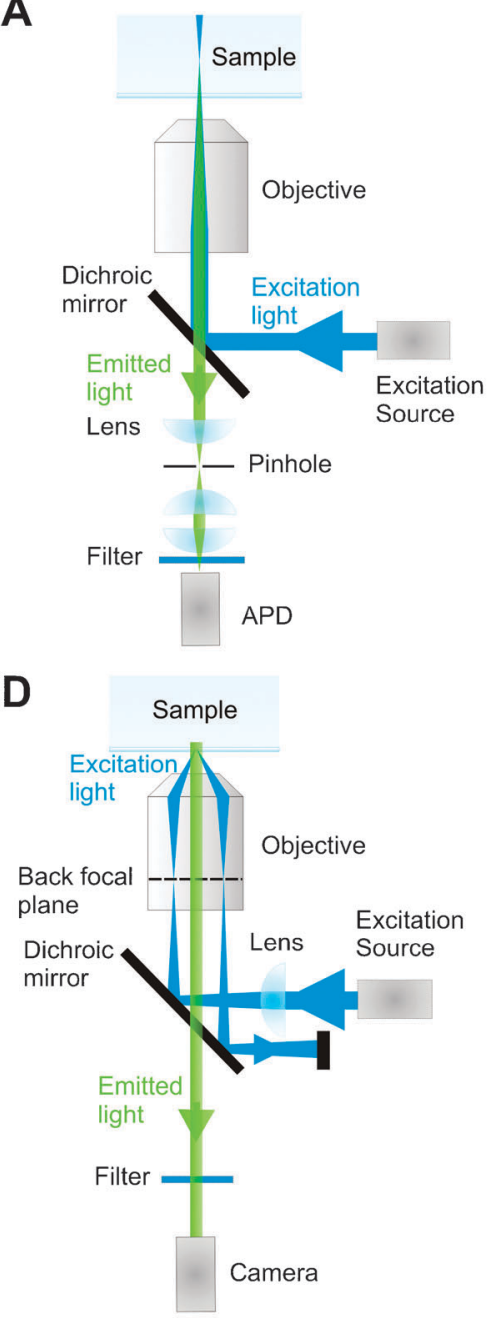

B

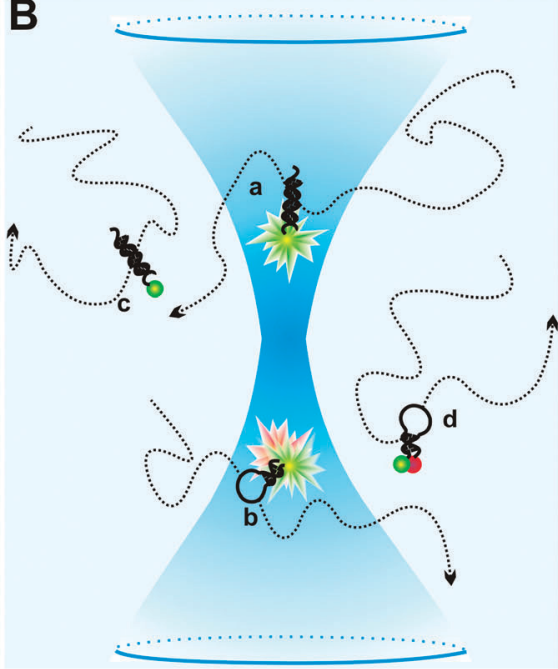

E

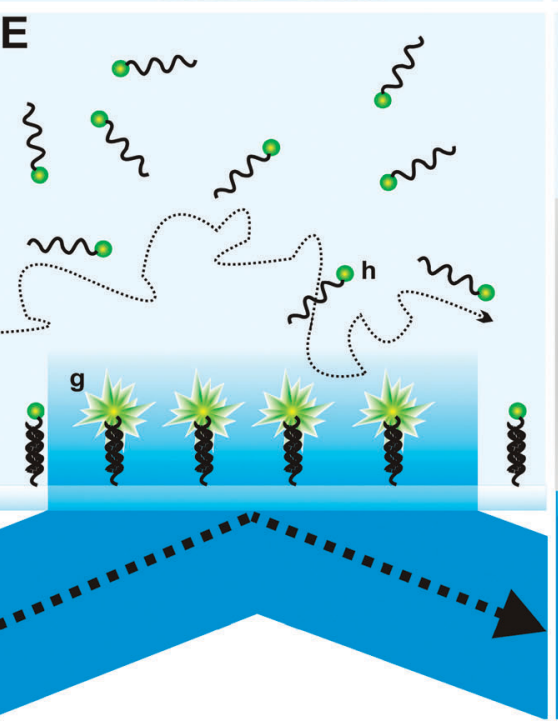

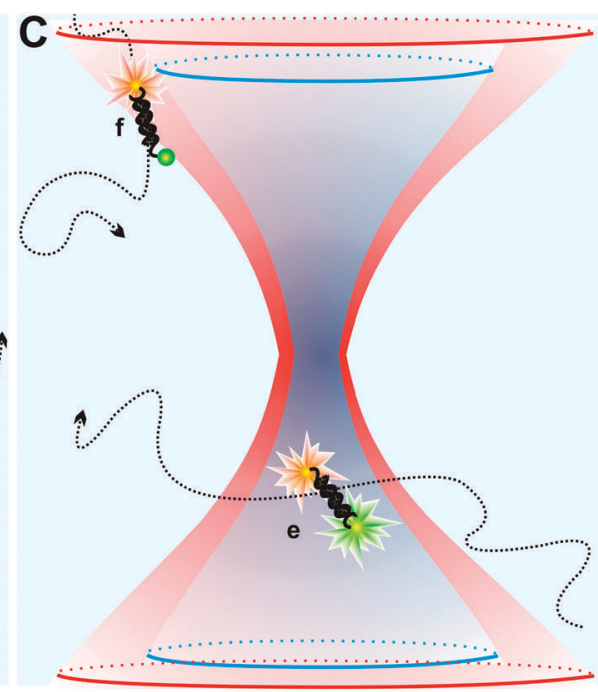

$\mathbf{F}$

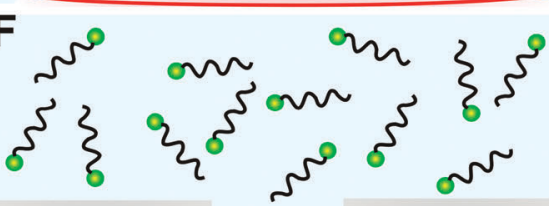

Fig. 3 Configurations for SMFS. (A) Confocal microscope setup. (B) Detection of single molecules diffusing through a confocal illumination volume $(\sim 1 \mu \mathrm{m}$ diameter, $\sim 0.5 \mathrm{fL})$. Molecules that are labelled with a fluorophore that can be excited by the laser wavelength can give rise to a fluorescence burst in one colour (molecule a), or two colours (molecule b) if undergoing Förster resonance energy transfer (FRET). If the path of the molecule does not take it through the illuminated volume, no emission occurs (molecules c and d). (C) Detection using two overlapped laser beams. Dual-labelled species that encounter the overlapped region during Brownian motion exhibit fluorescence from both reporters (molecule e), while some molecules are only excited by one laser due to imperfect overlap (molecule f). (D) Objective-based TIRFM setup. (E) Detection of fluorescence by TIRFM on a microscope slide. Due to the evanescently-decaying illumination field (depth $\approx 100 \mathrm{~nm}$ ), only surface-bound species (molecule g) are excited for long enough to generate a significant signal above background, whereas mobile species (molecule h) encounter the illuminated volume only briefly due to Brownian motion and therefore do not build up a significant signal above noise in any given pixel when averaged over the duration of the measurement. (F) Detection of a single molecule inside a nanofabricated ZMW (diameter 20-100 nm), with an illuminated volume of $10-20 \mathrm{zL}$.

fluctuations in intensity, where the detection volume can be occupied by multiple fluorophores. It is most useful in analysis of more concentrated samples in the $1-100 \mathrm{nM}$ range. ${ }^{16,22}$ Since these fluctuations are due to molecules diffusing in and out of the detection volume, the autocorrelation function, $G(\tau)$, that is generated enables measurement of diffusion coefficients and molecular dynamics, for example in ss- and dsDNA. ${ }^{23}$ FCS is most effective at distinguishing species with very large differences in molecular weight (and therefore hydrodynamic radius), which limits its usefulness in molecular diagnostics. For this reason, fluorescence cross correlation spectroscopy (FCCS), first proposed in 1994, ${ }^{24}$ was developed and first realised in $1997 .^{25}$ In this technique, two lasers are focussed into the same confocal volume, and the fluctuation in fluorescence from two separately excited dyes can be compared, which indicates whether they are co-localised (Fig. 3C). FCCS has been used to monitor PCR in which the forward and reverse primers are labelled with different dyes that therefore become associated in the amplicon. ${ }^{26}$ The related two colour coincidence detection (TCCD) experiment extends the sensitivity to $\mathrm{fM}$ concentrations. ${ }^{27}$ It is perhaps worth emphasising for readers who are unfamiliar with SMFS that bulk measurements cannot reveal association in these systems since there is no change in the fluorescence intensity of either 
reporter; it is only with the spatial and temporal resolution offered by SMD that such information can be obtained.

As well as confocal optics, two other illumination methods important in bioanalytical devices are TIRFM and ZMWs, both of which rely on evanescent waves to generate a very small illumination volume. In TIRFM, excitation light is directed either by a prism or a microscope objective (as in Fig. 3D) to a slide or coverslip at an angle greater than the critical angle, so that total internal reflection occurs. As a result, the excitation beam does not propagate into the sample, but an exponentially decaying evanescent wave at the interface penetrates the sample generating a thin film of illumination $(\sim 100 \mathrm{~nm})$ where its intensity is sufficient to excite fluorophores (Fig. 3E). ${ }^{28,29}$ ZMWs are nanofabricated cylindrical holes in a metal film, whose diameter $(20-100 \mathrm{~nm})$ is much smaller than the wavelength of the excitation light (Fig. 3F). Under these conditions there are no propagating modes, and an exponentially-decaying evanescent field produces an illuminated volume of $\sim 20 \mathrm{zL}$. In contrast to confocal optics then, an average of one molecule in the detection volume is produced by an analyte concentration of $83 \mu \mathrm{M}$ and single molecule detection of coumarin-labelled dCTP at $10 \mu \mathrm{M}$ can be achieved. ${ }^{30}$

\section{SMFS in microfluidic devices}

The ability to detect single molecules opens up the possibility of directly detecting nucleic acids without the need for enzymatic amplification. Quantifying DNA without using PCR, or RNA without RT-PCR, could offer several advantages. Firstly, the amplification process can produce artifacts, ${ }^{31,32}$ which would be negated by direct detection. This problem is particularly important in multiplex PCR, where the increased probability of primer-dimer formation or mispriming generally limits the number of simultaneous reactions to 10-20. ${ }^{33-35}$ Additionally, when biological samples are used, the presence of PCR inhibitors in the matrix such as urea from urine, ${ }^{36}$ melanin from skin, ${ }^{37}$ and immunoglobulin $\mathrm{G}(\mathrm{IgG}),{ }^{38}$ haemoglobin or lactoferrin ${ }^{39}$ from blood can obfuscate the results. Though these contaminants can be removed by sample pre-processing, ${ }^{40}$ this would add another layer of complexity to integrated analysis instruments. Finally, 'while-you-wait' point-of-care applications or detection of bioterrorism agents place exacting demands on the total assay time. Even though rapid cycle real time PCR reactions are routinely completed in $<30$ minutes ${ }^{41}$ and reaction times in continuous flow microfluidic devices can be shortened to 10-20 minutes while maintaining acceptable yields of the product, ${ }^{42,43}$ eliminating this step altogether would be advantageous in these contexts. Cepheid's GeneXpert system, which integrates sample preparation and real time PCR, can produce results in $\sim 1$ hour, while ultrasensitive platforms requiring less rigorously purified nucleic acid and a single hybridisation reaction rather than multiple thermal cycles may be able to provide data much more rapidly.

However, having a detection limit of one molecule does not guarantee access to an ultrasensitive molecular diagnostics technology, particularly one with high throughput. Any analytical test must provide a statistically significant level of confidence in the readout, which may be the presence or absence of a sequence, or its concentration. In SMFS techniques, this depends upon observing a greater number of events in the presence of nucleic acid than in its absence. Due to the small illuminated volumes necessary for SMD, low concentrations of analytes require extended acquisition times before this condition is satisfied. In confocal measurements in open volumes, for example, this is caused by the low diffusionlimited encounter rate of dilute fluorescent species with the femtolitre-sized detection volume. The time required to detect a sample of a given concentration with a set confidence interval can be calculated using Poisson statistics and the measured event rates in the presence and absence of the analyte. Li et al. estimated the time required to detect the presence or absence of dual-labelled DNA by TCCD at $1 \mathrm{pM}$ and $100 \mathrm{fM}$ with $99 \%$ confidence to be 2 and 60 minutes respectively. ${ }^{27}$ How does this compare with the throughput of PCR? Let us consider human genomic DNA sampled using a buccal swab. The expected yield from this procedure is approximately $1 \mu \mathrm{g} .{ }^{44}$ Even if the nucleic acid is concentrated to $5 \mu \mathrm{L}$, this still represents a concentration of only approximately $100 \mathrm{fM}$, requiring an analysis time of $\sim 1$ hour: approximately twice the length of time required to carry out a real time PCR assay. It is likely then, that to compete with PCR in throughput, it is necessary to devise ways to enhance the rate of data acquisition possible in SMD.

The problem of rapid detection of rare analytes is one of the major drivers for the development of systems which employ SMD in microfluidics, since flowing the fluorescent molecules through the detection volume either by pressure-driven or electrically-driven means could greatly enhance the encounter rate and hence reduce the analysis time dramatically. In addition to this advantage, the use of microfluidics in ultrasensitive diagnostic devices offers other potential benefits, such as efficient handling of small sample volumes and the possibility of cheap mass production. ${ }^{45,46}$ The paradigm of combined microfluidics and SMD was described in one review as "the holy grail of $\mu$ TAS" (micro total analysis systems), ${ }^{47}$ and has received considerable interest in the last 5-10 years. ${ }^{48}$ In fact, microfluidics were used in the early development of ultrasensitive fluorescence detection, where the flow cell of a fluorescence activated cell sorter (FACS) was interfaced with confocal detection optics (Fig. 4A), first in the detection of several thousand Rhodamine $6 \mathrm{G}$ chromophores, ${ }^{49,50}$ then single molecules of phycoerythrin, ${ }^{51}$ and finally single Rhodamine $6 \mathrm{G}$ molecules. ${ }^{11}$ In these examples, hydrodynamic focussing led to a sample stream diameter of $\sim 10 \mu \mathrm{m}$, which is larger than the excitation beam waist. As a result, not all of the molecules flowed through the device could be detected. Since then, various schemes to increase the proportion of molecules detected by forcing more of the analyte through the detection volume have been pursued. Improved hydrodynamic focussing, ${ }^{52}$ narrow capillaries, ${ }^{52,53}$ electrokinetic forces (Fig. 4B) ${ }^{54}$ oil-in-water microdroplet streams (Fig. 4C), ${ }^{55,56}$ and nanofabricated channels (Fig. 4D) $)^{57-59}$ have all been used to confine the sample and thus enhance the detection efficiency. An alternative approach uses cylindrical optics to expand the detection volume in a single dimension, generating a sheet-like illumination volume which can increase the 
A

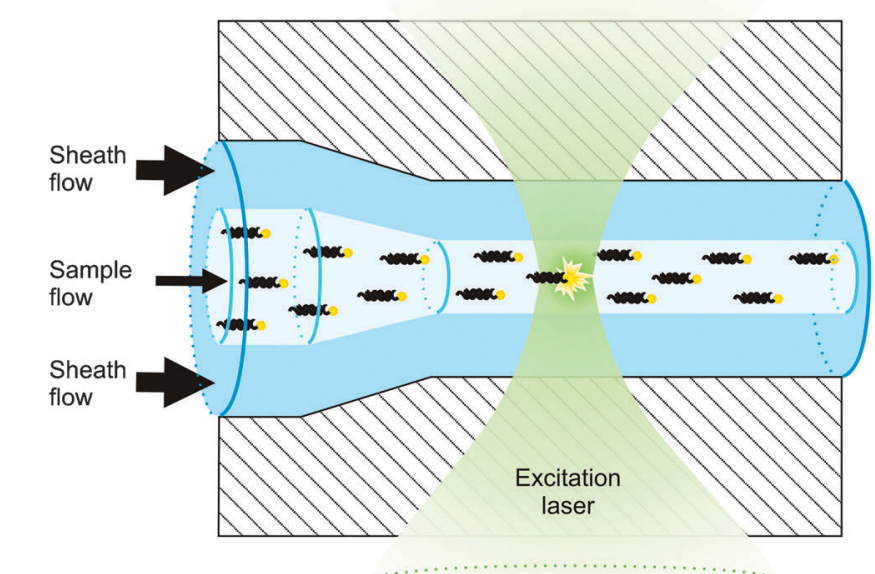

B

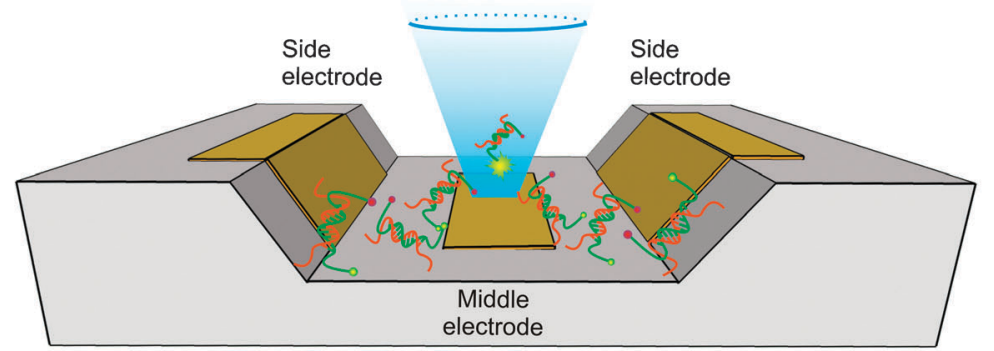

D

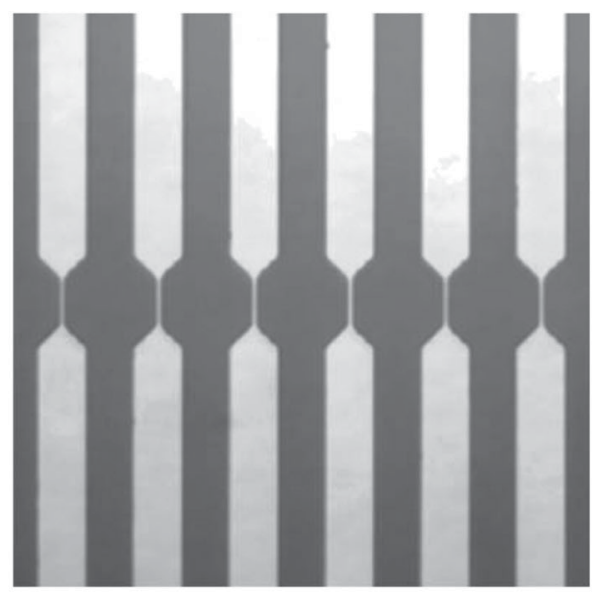

E

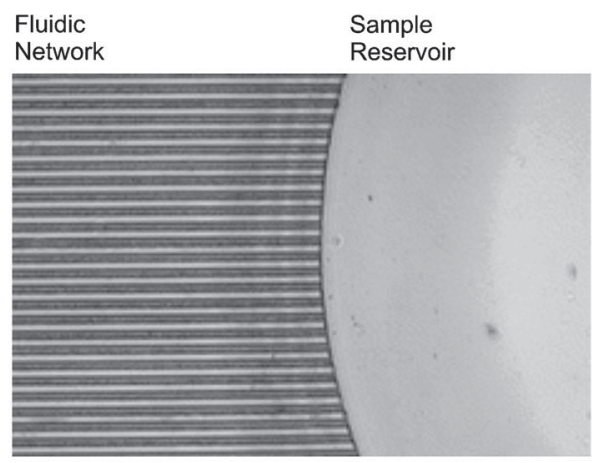

C
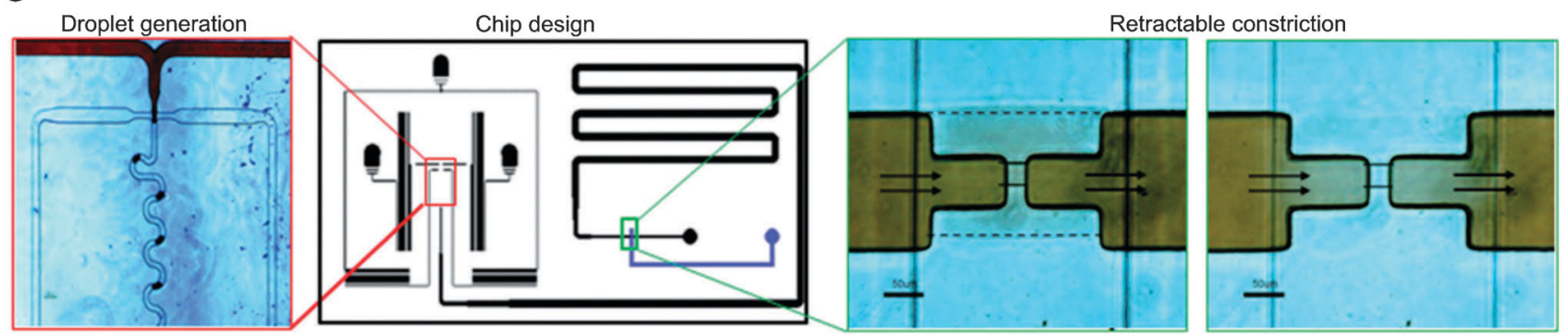

Fig. 4 Microfluidic devices for SMD in flow. (A) Modified FACS flow cell using hydrodynamic focussing. (B) Device for combined hydrodynamic/electrokinetic focussing of nucleic acid molecules. (C) Device for SMFS in oil-in-water microdroplets, with retractable channel constriction for confinement of droplets causing increased illumination time required for SMD. Reproduced from ref. 56. (D) Nanofabricated channels narrowing from a width of $10 \mu \mathrm{m}$ to $500 \mathrm{~nm}$ for a length of $10 \mu \mathrm{m}$. Reproduced from ref. 59. (E) Analysis chip with multiple microchannels ( $30 \mu \mathrm{m}$ width) for high throughput parallel SMD. Reproduced from ref. 62.

detection efficiency to $\sim 100 \%$ in larger microchannels with a width of $100 \mu \mathrm{m} .{ }^{60}$ Using a combination of hydrodynamic and electrokinetic focussing, Wang and co-workers estimated that the acquisition time required to detect $70 \mathrm{pM}$ of unlabelled single stranded DNA hybridised to a complementary molecular beacon with $99 \%$ confidence dropped from $\sim 200 \mathrm{~s}$ to $<4 \mathrm{~s}$ due to the greater encounter rate achieved. ${ }^{54}$

In devices such as these, the throughput is effectively limited by the fluorescence lifetime (in the nanosecond range for organic dyes) because the residence time of a fluorophore in the detection volume is inversely proportional to its velocity, ${ }^{61}$ meaning that fewer photons can be emitted per molecule as the flow rate is increased. For example, Foquet et al. were able to achieve SMD in submicrometre-sized fluidic channels using electrokinetic flow speeds up to $10 \mathrm{~cm} \mathrm{~s}^{-1}$ but noted the requirement for precise alignment of the laser focus with the channel and a marked decrease in the number of detected photons due to the decreased illumination time $(10 \mu \mathrm{s}){ }^{58}$ Okagbare and Soper have proposed an alternative method for achieving high throughput SMD, using widefield illumination to image thirty microfluidic channels simultaneously (Fig. 4E) ${ }^{62}$ Modest flow rates $\left(\sim 0.01 \mathrm{~cm} \mathrm{~s}^{-1}\right)$ were used, but the highly parallel nature of the measurement could allow detection of up to $\sim 7.65 \times 10^{6}$ molecules $\mathrm{s}^{-1}$ using narrower channels. The use of microfluidics also enables sample manipulations that can improve detection efficiency, such as deoxygenation for enhanced single pair FRET (spFRET) measurements, ${ }^{63}$ recirculation of the sample through a $\mathrm{nL}$ chamber allowing each molecule to be counted multiple times, ${ }^{64}$ and concentration of target nucleic acid prior 
to hybridisation by micro-evaporation. The combination of the last two processes allowed detection of ssDNA at initial concentrations as low as $50 \mathrm{aM}$ in an acquisition time of $100 \mathrm{~s}$ after concentration. ${ }^{65}$ It should be noted that the evaporation step reported required a prohibitive $20 \mathrm{~h}$, though it may be possible to reduce this significantly by modification of the operating parameters.

\section{Selection of fluorescent labels for SMFS}

Researchers who practise SMFS tend to work from a smaller palette of fluorophores than those carrying out ensemble measurements, who have a wide variety of labels at their disposal. ${ }^{66}$ This is largely because the short occupation time of fluorophores in the illuminated volume and the high illumination intensities used in SMD place exacting demands on the photophysical properties of the dye. The number of photons emitted by a reporter is ultimately limited by the number of excitation/emission cycles it can complete while in the detection volume, which in turn depends on its transit time across the detection volume and its characteristic fluorescent lifetime, since the molecule must return to its ground state before another excitation photon can be absorbed. High illumination intensities $\left(>10^{8} \mathrm{~kW} \mathrm{~cm}{ }^{-2}\right)$ are used in SMD to ensure that the fluorophore is excited rapidly after relaxation. When analytes are undergoing Brownian motion, the duration as well as the rate of their encounters with a femtolitre detection volume are determined by their diffusion coefficients. A mean transit time of around $100 \mu$ s is typical for short DNA duplexes. ${ }^{67}$ Given a fluorescence lifetime of $4 \mathrm{~ns}$, a maximum of 25000 photons could be emitted in this time. These propagate in all directions, although high NA objectives can collect a relatively high fraction of emitted photons (e.g. $26 \%$ of photons for NA $=1.3$ ), it has been reported that once inefficiencies in the detector and other components are taken into account, an overall efficiency as low as $\sim 1 \%$ is achieved, ${ }^{68}$ i.e. 250 photons. When molecules are driven through the probe volume by flow, the occupation time may be even shorter, hence even fewer photons may be emitted. These numbers are further limited by quantum efficiency and bleaching effects or transitions into dark states. To obtain the maximum signal from a label, it is therefore important that the reporter displays a large extinction coefficient, high quantum yield, good photostability at high laser power and a short excited state lifetime. These considerations mean that fluorophores selected for SMFS studies must meet stringent selection criteria.

Since laser induced fluorescence (LIF) is the most suitable excitation mode for SMD, the dyes that have been most widely used are those efficiently excited by most common lasers; among these are the argon ion (488 $\mathrm{nm}$ ), frequency doubled $\mathrm{Nd}$ :YAG $(532 \mathrm{~nm})$, krypton ion $(568 \mathrm{~nm})$ and $\mathrm{HeNe}(633 \mathrm{~nm})$ laser sources. Initially, the familiar historic dyestuffs (fluoresceins, rhodamines and cyanines) were used, though these have largely been superseded by superior synthetically modified versions, available from many suppliers (Invitrogen, ATTO TEC, GE Healthcare, Glen Research, Lumiprobe and Dyomics among others), each of which offer distinct patented fluorophore structures (Fig. 5, Table 1). Reactive derivatives available for labelling of oligonucleotides include phosphoramidites for incorporation during automated synthesis, carboxylic acids and active esters for reaction with aminomodified oligonucleotides, maleimides and iodoacetamides for labelling thiolated nucleic acids, and amines for coupling to carboxylic acids and electrophiles. In addition to these reagents, azide- and alkyne-functionalised fluorophores are becoming increasingly available to take advantage of the efficient conjugation possible via $\mathrm{Cu}$ (I)-catalysed click chemistry, which is becoming a well-established methodology for synthetic manipulations of nucleic acids. ${ }^{69}$ In general, labelling by phosphoramidite chemistry is the most preferable due to the high coupling yields obtained. However, most chromophores suitable for SMFS (particularly rhodamines and cyanines) are unstable to oligonucleotide deprotection in concentrated aqueous ammonia or other basic media, in which case post-synthetic modification is necessary.

In the first demonstration of SMD, 80-100 fluorescein molecules were conjugated to a single $\gamma$-globulin molecule via a polyethyleneimine linker and detected following excitation by an Ar ion laser. ${ }^{10}$ Despite its widespread use in many applications, fluorescein is not now widely used in SMFS due to its susceptibility to photobleaching (of most importance in imaging applications) and the $\mathrm{pH}$-dependence of its quantum yield, which is due to ionisation of the phenolic group $\left(\mathrm{p} K_{\mathrm{a}}\right.$ 6.4). In order to improve fluorescence at neutral $\mathrm{pH}$, the 2,7-difluoro derivative of fluorescein, Oregon Green, was synthesised. The electron withdrawing effect of the fluorine atoms reduces the $\mathrm{p} K_{\mathrm{a}}$ to 4.8 , making this dye suitable for detection at or below $\mathrm{pH} 7 .^{70}$

Dyes from the rhodamine family are perhaps the most commonly studied by SMFS, and many derivatives are available. The first detection of single fluorophores in aqueous conditions twenty years ago was of a $100 \mathrm{fM}$ solution of Rhodamine $6 \mathrm{G}$ excited at $532 \mathrm{~nm},{ }^{11}$ and sulfonated/ elaborated derivatives of that dye, Alexa Fluor 532 and ATTO 532, remain popular in the present day. ${ }^{71}$ For excitation at $488 \mathrm{~nm}$, Rhodamine Green (Rhodamine 110) or its sulfonated derivatives Alexa Fluor 488 or ATTO 488 are commonly used; these labels are preferred to fluorescein derivatives, because they are completely insensitive to $\mathrm{pH}$ in the useful analytical range, 4-8. Due to the instability of the rhodamine chromophore, its incorporation during oligonucleotide synthesis has to be carried out carefully, using $0.05 \mathrm{M} \mathrm{K}_{2} \mathrm{CO}_{3}$ or tert-butylamine/methanol/water $(1: 1: 2)$ for deprotection. ${ }^{72}$

The introduction of sulfonate groups is a common strategy for improving the performance of fluorophores. ${ }^{73,74}$ The reduced hydrophobicity results in increased water solubility and a lower tendency to form aggregates in water. While aggregate formation is not a major concern at the low concentrations typically used for SMFS, dye molecules may interact with each other intramolecularly if bioconjugates are multiply-labelled, or otherwise with hydrophobic amino acid side chains or nucleobases, adversely affecting fluorescence properties. ${ }^{75-77}$ High water solubility is particularly important for efficient post-synthetic labelling of deprotected oligonucleotides, though not for incorporation in oligonucleotide synthesis, where acetonitrile is the solvent of choice. For this reason the sulfonate groups of $\mathrm{Cy} 3, \mathrm{Cy} 5$ and $\mathrm{Cy} 5.5$ are absent 


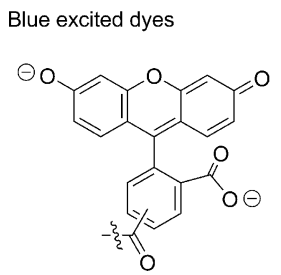

Fluorescein

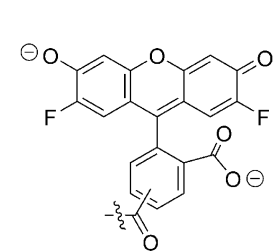

Oregon Green

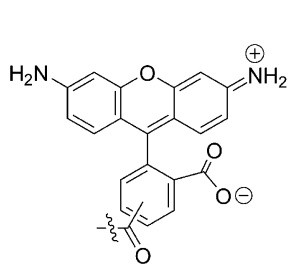

Rhodamine Green (Rhodamine 110)

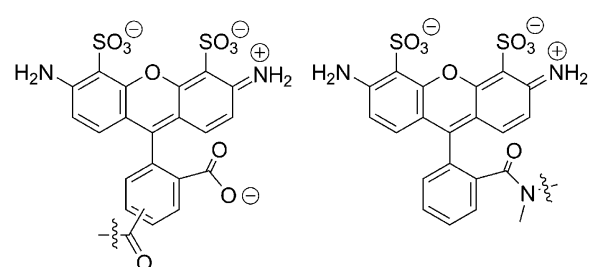

Alexa Fluor 488

ATTO 488

Green excited dyes

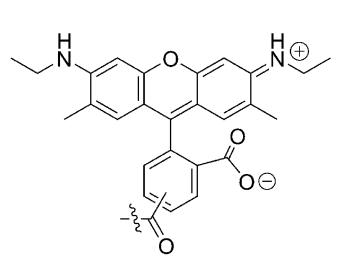

Rhodamine 6G<smiles></smiles>

TAMRA

Red/far red excited dyes<smiles></smiles><smiles>[Y17]C(=O)c1ccccc1C1=c2cc3c4c(c2C(C)(C)c2cc5c(cc21)C(C)CC(C)(C)N5CC)CCC[N+]=4CCCC3</smiles>

ATTO 647N<smiles></smiles>

Alexa Fluor 532<smiles>[Y]CCCN1c2ccc([R])cc2C(C)(C)C1/C=C/C=C1\N([Y4]([Y])([H])C)c2ccc([R])cc2C1(C)C</smiles>

Cy3

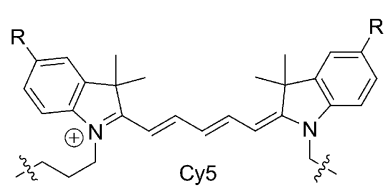<smiles></smiles>

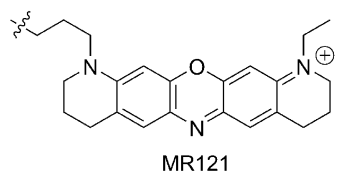<smiles></smiles>

ATTO 532<smiles>CC(=O)Cc1ccc2c(c1)C(C)(C)C1=C3C=C4C5Nc6ccc(O[O-])cc6C(C)(C)C5CCN4[C@@H]3CCC1O2</smiles>

Сузв

Fluorescent intercalators

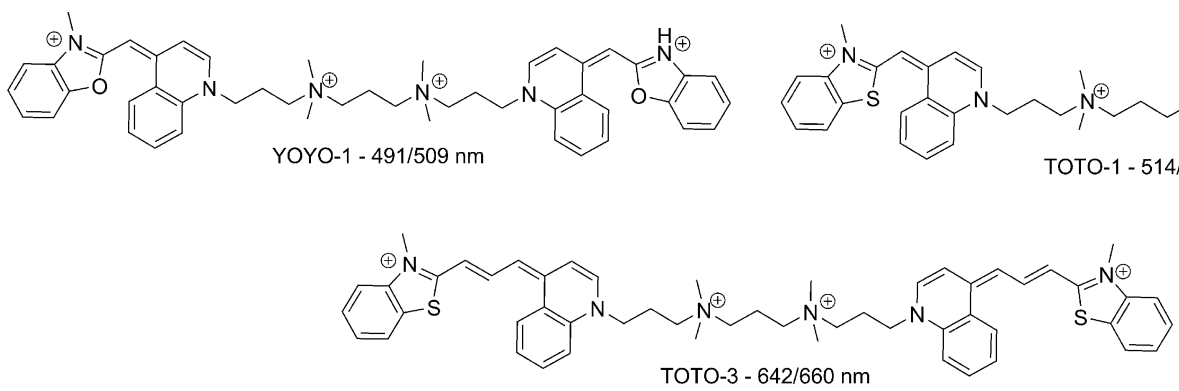

Fig. 5 Chemical structures of fluorophores commonly used in SMFS. For phosphoramidite derivatives of Cy3, Cy5 and Cy5.5, R = H; for other reactive derivatives, $\mathrm{R}=\mathrm{SO}_{3}{ }^{-}$. 
Table 1 Fluorescence properties of organic fluorophores commonly used in SMFS. Parameters are reported for the free dyes and may be significantly altered upon conjugation to nucleic acids

\begin{tabular}{|c|c|c|c|c|c|c|}
\hline Dye & $\lambda_{\mathrm{ex}} / \mathrm{nm}$ & $\lambda_{\mathrm{em}} / \mathrm{nm}$ & $\varepsilon / \mathbf{M}^{-1} \mathrm{~cm}$ & $\Phi$ & $\tau / \mathrm{ns}$ & Available reactive derivatives \\
\hline Fluorescein $^{\mathrm{R}, 97}$ & 490 & 514 & 75000 & 0.92 & 4.1 & -NCS, $-\mathrm{CO}_{2} \mathrm{H}, \mathrm{NHS}$ ester, $-\mathrm{NH} 2,-\mathrm{N}_{3}$, maleimide, phosphoramidite \\
\hline Oregon Green ${ }^{\mathrm{S}, \mathrm{I}}$ & 490 & 514 & 82400 & 0.97 & 4.1 & $-\mathrm{CO}_{2} \mathrm{H}$, NHS ester, $-\mathrm{NH}_{2}$, maleimide, $-\mathrm{N}_{3}$, -alkyne, -iodoacetamide \\
\hline Alexa Fluor $488^{\mathrm{S}, \mathrm{I}}$ & 495 & 519 & 73000 & 0.92 & 4.1 & $-\mathrm{CO}_{2} \mathrm{H}$, NHS ester, $-\mathrm{NH}_{2}$, maleimide, $-\mathrm{N}_{3}$, -alkyne, -iodoacetamide \\
\hline ATTO $488^{\mathrm{S}, \mathrm{A}}$ & 501 & 523 & 90000 & 0.80 & 3.2 & $-\mathrm{CO}_{2} \mathrm{H}$, NHS ester, $-\mathrm{NH}_{2}$, maleimide, $-\mathrm{N}_{3}$, -iodoacetamide \\
\hline $\begin{array}{l}\text { Rhodamine Green } \\
\text { (Rhodamine 110) }\end{array}$ & $504^{\mathrm{S}, \mathrm{I}}$ & $532^{\mathrm{S}, \mathrm{I}}$ & $73000^{\mathrm{S}, \mathrm{I}}$ & $0.92^{\mathrm{R}, 98}$ & $4.2^{\mathrm{R}, 99}$ & $-\mathrm{CO}_{2} \mathrm{H}, \mathrm{NHS}$ ester \\
\hline Rhodamine $6 \mathrm{G}$ & $524^{\mathrm{S}, \mathrm{I}}$ & $552^{\mathrm{S}, \mathrm{I}}$ & $92000^{\mathrm{S}, \mathrm{I}}$ & $0.95^{\mathrm{R}, 98}$ & $4.08^{\mathrm{R}, 100}$ & $-\mathrm{CO}_{2} \mathrm{H}, \mathrm{NHS}$ ester \\
\hline Alexa Fluor $532^{\mathrm{S}, \mathrm{I}}$ & 531 & 554 & 81000 & 0.61 & 2.5 & NHS ester, maleimide \\
\hline ATTO $532^{\mathrm{S}, \mathrm{A}}$ & 532 & 553 & 115000 & 0.90 & 3.8 & $-\mathrm{CO}_{2} \mathrm{H}$, NHS ester, $-\mathrm{NH}_{2}$, maleimide, $-\mathrm{N}_{3}$, -iodoacetamide \\
\hline TAMRA $^{\mathrm{R}, 97}$ & 547 & 574 & 77000 & 0.35 & 2.2 & $\begin{array}{l}-\mathrm{NCS},-\mathrm{CO}_{2} \mathrm{H}, \mathrm{NHS} \text { ester, }-\mathrm{NH}_{2},-\mathrm{N}_{3} \text {, alkyne, } \\
\text { maleimide, phosphoramidite }\end{array}$ \\
\hline $\mathrm{Cy} 3^{\mathrm{R}, 82}$ & 548 & 562 & 150000 & 0.04 & $<0.3$ & $\begin{array}{l}-\mathrm{CO}_{2} \mathrm{H} \text {, NHS ester, }-\mathrm{NH}_{2} \text {, maleimide, }-\mathrm{N}_{3} \text {, } \\
\text {-iodoacetamide phosphoramidite }\end{array}$ \\
\hline $\mathrm{Cy} 3 \mathrm{~B}^{\mathrm{R}, 82}$ & 558 & 572 & 130000 & 0.70 & 2.8 & $-\mathrm{CO}_{2} \mathrm{H}$, NHS ester, maleimide \\
\hline $\mathrm{Cy} 5^{\mathrm{S}, \mathrm{G}}$ & 646 & 664 & 250000 & 0.27 & 1.0 & $\begin{array}{l}-\mathrm{CO}_{2} \mathrm{H}, \text { NHS ester, }-\mathrm{NH}_{2} \text {, maleimide, }-\mathrm{N}_{3} \text {, } \\
\text {-iodoacetamide phosphoramidite }\end{array}$ \\
\hline Alexa Fluor $647^{\mathrm{S}, \mathrm{G}}$ & 650 & 668 & 270000 & 0.33 & 1.0 & $\begin{array}{l}-\mathrm{CO}_{2} \mathrm{H}, \mathrm{NHS} \text { ester, }-\mathrm{NH}_{2} \text {, maleimide, }-\mathrm{N}_{3}, \\
\text {-alkyne, -iodoacetamide }\end{array}$ \\
\hline ATTO $647 \mathrm{~N}^{\mathrm{S}, \mathrm{A}}$ & 644 & 669 & 150000 & 0.65 & 3.4 & $\begin{array}{l}-\mathrm{CO}_{2} \mathrm{H}, \text { NHS ester, }-\mathrm{NH}_{2} \text {, maleimide, }-\mathrm{N}_{3} \text {, } \\
\text {-iodoacetamide }\end{array}$ \\
\hline $\mathrm{Cy} 5.5^{\mathrm{S}, \mathrm{G}}$ & 673 & 692 & 190000 & 0.23 & 1.0 & $\begin{array}{l}-\mathrm{CO}_{2} \mathrm{H}, \text { NHS ester, }-\mathrm{NH}_{2} \text {, maleimide, }-\mathrm{N}_{3} \text {, } \\
\text {-iodoacetamide phosphoramidite }\end{array}$ \\
\hline
\end{tabular}

$\mathrm{S}$ - spectroscopic data provided by the supplier $(\mathrm{I}=$ Invitrogen, $\mathrm{A}=$ ATTO-TEC, $\mathrm{G}=$ GE Healthcare $)$. $\mathrm{R}$-spectroscopic data taken from the literature $(n=$ reference number).

in their phosphoramidite derivatives. In contrast, Alexa Fluor 647, a cyanine dye related to Cy5, bears four sulfonate groups, ${ }^{78}$ and is particularly resistant to self-quenching in protein conjugates with a high degree of labelling. ${ }^{79}$

While cyanine dyes are widely used for labelling of nucleic acids, they display photoswitching behaviour with a complex mechanism involving sticking/unsticking to DNA, transition to triplet states and cis/trans isomerisation. A number of these states are non-fluorescent, leading to blinking and the generation of a large 'zero peak' in spFRET measurements. ${ }^{78}$ This property is displayed by $\mathrm{Cy} 3, \mathrm{Cy} 5$ and the tetrasulfonated Alexa Fluor 647. While blinking phenomena can be exploited for imaging beyond the diffraction limit, ${ }^{80,81}$ these processes are generally undesirable for the analytical applications discussed here because they reduce the detection efficiency. To eliminate effects due to photoisomerisation, $\mathrm{Cy} 3 \mathrm{~B}$, a conformationally locked analogue of $\mathrm{Cy} 3$, has been developed. ${ }^{82}$ This modification has a dramatic effect on the quantum yield, which increases from 0.04 for $\mathrm{Cy} 3$ to 0.7 for Cy3B. This fluorophore has been shown to be an efficient donor in spFRET experiments. ${ }^{83}$ For detection in the far red part of the spectrum the carbopyronine dye, ATTO $647 \mathrm{~N},{ }^{84}$ is a conformationally rigid alternative to Cy5 and Alexa Fluor 647.

Fluorescent intercalators are alternative labels for SMD of DNA, obviating the need for chemical derivatisation of oligonucleotides. Dimeric cyanine dyes, such as YOYO-1 and TOTO-1, are usually preferred for SMFS due to their high affinity for dsDNA, large fluorescence enhancements upon binding and the availability of many derivatives whose absorption spectra enable efficient excitation by widely used laser sources. ${ }^{85}$ However, their use in SMFS is usually limited to the staining of single polynucleotides with many bound intercalators, ${ }^{61,86-89}$ rather than the specific detection of short sequences of most interest in genetic analysis.
Quantum dots, luminescent core-shell semiconductor nanocrystals of diameter $2-10 \mathrm{~nm}$, have been the subject of much interest since the first descriptions of their use in biological imaging in the late 1990s. ${ }^{90,91}$ The most popular core materials in analytical applications are CdSe and CdTe, among the first to be synthesised. Commercial suppliers (e.g. Quantum Dot Corporation, now owned by Invitrogen, Evident Technologies and Crystalplex) can provide capped core-shell nanoparticles, and particles functionalised with groups such as streptavidin, amines and carboxylic acids, enabling conjugation to oligonucleotides. Their popularity in SMFS stems largely from their enhanced brightness, broad excitation spectra and resistance to photobleaching, but intermittent emission at the single molecule level caused by photoblinking can cause problems. ${ }^{92}$ Careful optimisation of surface chemistry to ensure stability and solubility in aqueous media is also required. Reviews comparing quantum dots with organic dyes, ${ }^{93}$ as well as describing their use in biomolecular assays and single molecule detection have recently been published, ${ }^{94-96}$ so we do not replicate this material here.

\section{Assays for ultrasensitive detection of nucleic acids}

With suitable instrumentation and labels available, the remaining requirement for ultrasensitive nucleic acid detection is an assay that generates a detectable signal in the presence of a specific sequence. Strategies used for real time PCR that rely on enzymatic modification of a probe by the polymerase for signal generation, either by hydrolytic cleavage, as in TaqMan, ${ }^{101}$ or extension of a primer element, as in Scorpions, ${ }^{102}$ or Amplifluor primers, ${ }^{103}$ are undesirable for amplification-free genetic analysis methods. Recently, assays that use rolling circle amplification combined with nicking endonuclease signal amplification (RCA-NESA), ${ }^{104}$ or 
exonuclease III, ${ }^{105}$ to cleave fluorogenic oligonucleotide probes have been proposed as ultrasensitive methods for DNA detection. The turnover of Molecular Beacons in the cleavage reactions means that multiple fluorescence signals can be generated by a single unlabelled target molecule. This process greatly increases the signal, leading to extremely low limits of detection ( $85 \mathrm{fM}$ and $20 \mathrm{aM}$ respectively) without the need for target amplification by polymerase enzymes. As a result, the risk of copying errors is removed, and less sophisticated equipment is required because the assays proceed under isothermal conditions and generate a signal detectable by bulk fluorescence spectroscopy. However, the linear nature of the signal amplification steps means that incubation times are unavoidably longer than the corresponding exponential process in PCR: $5 \mathrm{~h}$ for RCA-NESA and $20 \mathrm{~h}$ for the exonuclease III assay at $4{ }^{\circ} \mathrm{C}$. In the sections below, we have concentrated on methods that have the potential to provide sequence information on unlabelled nucleic acids of biological origin in short timescales. These are divided into three sections, based on the type of readout observed in the measurement.

\section{Intensity-based detection}

Detection based on an increase in fluorescence intensity in the presence of the target nucleic acid is perhaps the simplest approach conceptually. In the single molecule regime, this typically involves defining a threshold, then counting the number of events (either bursts of fluorescence or pixels, if imaging is used) whose intensity exceeds this level (Fig. 6A). As with real time PCR methods, staining with a fluorescent intercalator such as YOYO-1 can reveal the presence of double stranded DNA. ${ }^{56}$ This signal could be used to confirm sample quality, or for sizing of circulating nucleic acids (CNA) stained with TOTO-3 by analysis of burst sizes in flow, ${ }^{106}$ but cannot provide any sequence information.

Oligonucleotide probes that exhibit increased fluorescence upon hybridisation to their complementary sequence can provide sequence-specific information. Molecular Beacons, hairpin-structured oligonucleotides labelled with a fluorophore and quencher first described by Tyagi and Kramer for monitoring real time PCR reactions are one such probe type. ${ }^{107}$ When hybridised, a fluorophore and quencher at either end of the stem sequence become distal, causing the quantum yield of the reporter to increase significantly (Fig. 6B). As this mechanism of signal generation is not dependent on any enzymatic modification of the probe or target nucleic acid, it is therefore potentially compatible with amplification-free detection, resulting in significant interest in the use of Molecular Beacons in ultrasensitive methods. Zhang et al. used two Molecular Beacons, labelled with either Oregon Green/Iowa Black or Cy5/BHQ-3 for detection and discrimination of synthetic single stranded targets at concentrations down to $70 \mathrm{pM}$ by counting bursts above a suitable threshold from samples mounted on a microscope slide. ${ }^{108}$ The diffusionlimited encounter rate from static measurements using Molecular Beacons has been improved upon by the same group using pressure-driven or electrokinetic flow, improving the data acquisition rate as discussed previously. ${ }^{54,56}$
However, the use of intensity alone as a means to identify binding events has some inherent drawbacks. Given a high efficiency and throughput of detection, the sensitivity becomes limited by the background signal, i.e. the number of events above threshold in the absence of the target. For Molecular Beacon measurements, some of these result from imperfections in synthesis, such as the presence of hairpins that have not been labelled with a quencher, or contamination with residual free dye. Since most dyes compatible with SMFS are unstable to standard oligonucleotide deprotection conditions, the labelling reaction is typically carried out post-synthetically, with the deprotected oligonucleotide in solution. As a result, it is often difficult to completely remove the excess free dye used in the coupling reaction, even by HPLC. In addition, thermodynamic equilibrium necessitates a small fraction of open or 'melted' hairpins, even at temperatures below the $T_{\mathrm{m}}$, depending on the stem and loop sequences. ${ }^{67,109}$ While these can usually be neglected, their number will eventually become comparable to hybridised beacons as the concentration of the target becomes extremely small relative to the concentration of probes. Finally, the presence of autofluorescent impurities from the sample may also produce bursts above threshold.

Alternative designs that do not use an extrinsic fluorophorequencher pair therefore have advantages if the synthesis of the probes is simplified, as do detection methods using other parameters in addition to intensity. Smart probes for example, which rely on quenching of the fluorophore by an oligo-dG stem sequence, only require the incorporation of a single dye molecule (Fig. 6C). Quenching occurs via photoinduced electron transfer (PET) between the reporter (ATTO 655 or the oxazine dyes MR121 and JA242) and the stem, due to the low oxidation potential of guanine. ${ }^{110}$ In static confocal measurements, smart probe binding to target nucleic acids is monitored using three fluorescence parameters: intensity, fluorescence lifetime and residence time. ${ }^{111}$ Reduction in quenching by separation of the reporter and oligo-dG stem leads to increased intensity and excited state lifetime, while hybridisation to the target nucleic acid decreases the diffusion coefficient and hence prolongs the transit time through the excitation volume. The average residence time is increased from $\sim 100 \mu$ s for an unhybridised smart probe to $180 \mu$ s when hybridised to a $20 \mathrm{nt}$ synthetic DNA target, and to $380 \mu \mathrm{s}$ when bound to a $157 \mathrm{nt}$ PCR product. ${ }^{112}$ Using these properties as three AND criteria reduces the background event rate significantly, thereby enhancing sensitivity to a synthetic target from $1 \mathrm{nM}$ using intensity alone, to $1 \mathrm{pM}$ with multiparameter analysis. However, the residence time parameter could not be used in devices using SMD in fast flow, since diffusion becomes negligible under these conditions. ${ }^{61}$ When immobilised on a solid surface, functional smart probes could be distinguished from those adsorbed by surface-dye interactions by polarisation modulated excitation. This approach enabled detection of synthetic ssDNA at 0.1 pM. $^{113}$

Another synthetically simplified Molecular Beacon has been described by Conley et al., where quenching in the closed conformation is caused by formation of an H-dimer between two dicyanomethylenedihydrofuran (DCDHF) fluorophores. ${ }^{114}$ Blunt-ended hairpins modified with amino groups at the $3^{\prime}$ and $5^{\prime}$ termini are doubly-labelled using a DCDHF NHS-ester 
A

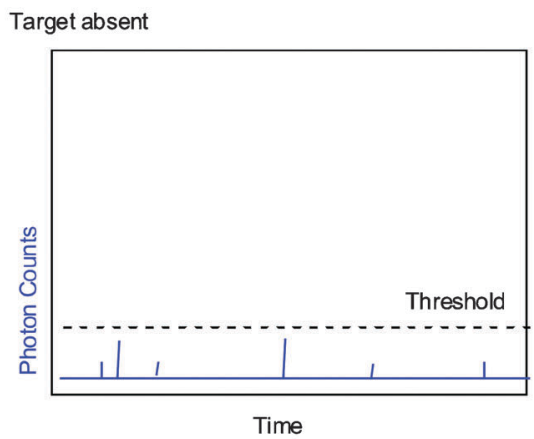

Target present

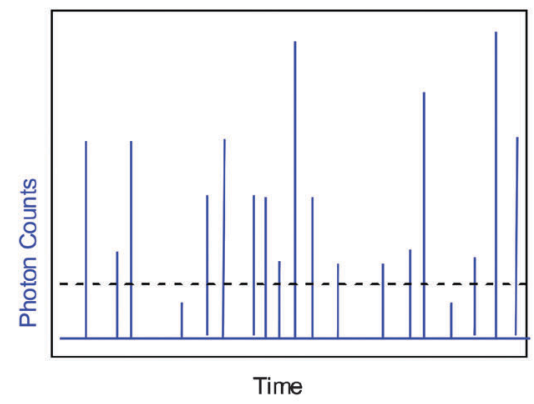

B
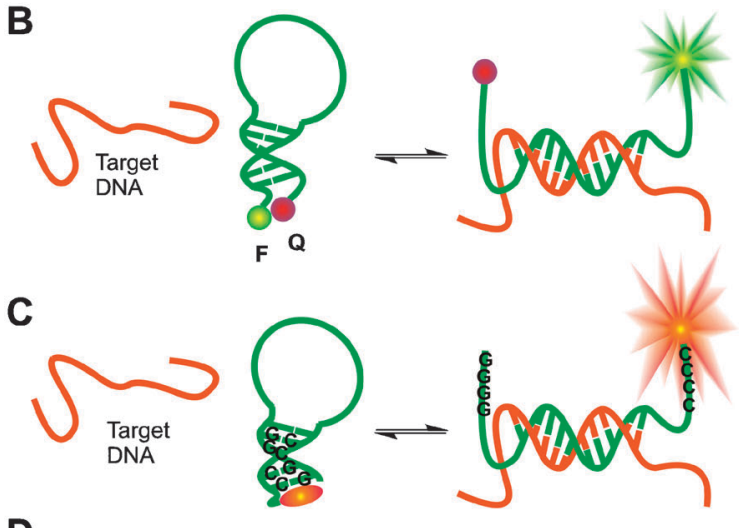

D
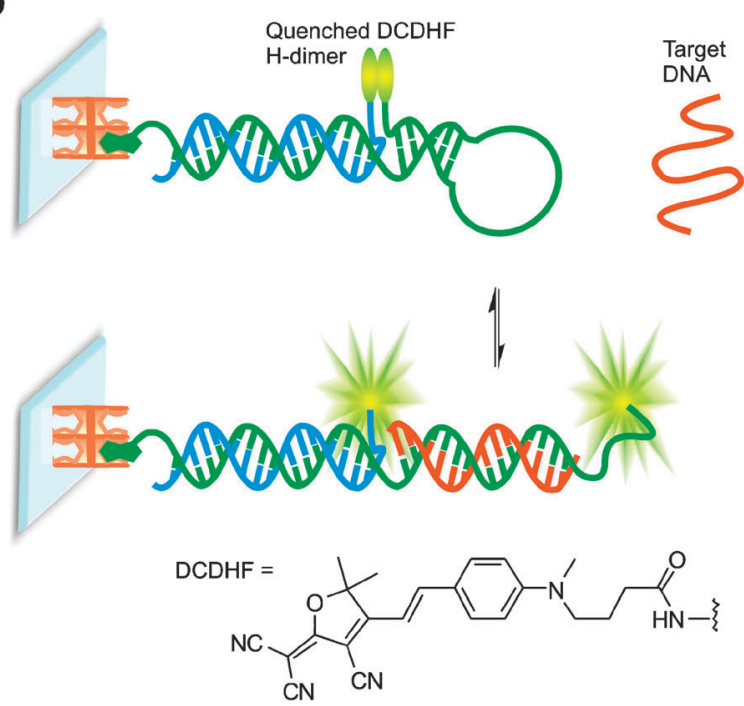

Fig. 6 (A) Intensity-based detection of nucleic acid targets. A greater number of fluorescence bursts above threshold are observed upon hybridisation. (B) Mode of action of Molecular Beacons (B), smart probes (C) and intermolecular quenched H-dimer probes (D). to form self-quenched intramolecular dimer (SQuID) Molecular Beacons, while two separately labelled oligonucleotides are used to form an immobilised intermolecular Molecular Beacon for single molecule imaging studies by TIRFM (Fig. 6D). When these beacons are opened by the target sequence, both chromophores exhibit increased fluorescence due to disruption of the $\mathrm{H}$-dimer. In the imaging detection mode, both reporters are observed within a single pixel, resulting in a two-step photobleaching signature that could be used to distinguish open beacons from spurious fluorescence. While the time required for photobleaching is relatively long (5-10 s per fluorophore pair), the bleaching of many immobilised beacons could be monitored simultaneously using widefield imaging, thereby increasing the detection throughput.

Another approach, reported by Castro et al., is to concentrate fluorescence from the solution onto the probe-target duplex, so that binding events are observed as highly emissive species above a constant background. ${ }^{115}$ This was achieved by incorporation of a dUTP derivative labelled with a TAMRA/ BODIPY FRET pair during polymerase extension of a single primer hybridised to a $1568 \mathrm{nt}$ polynucleotide fragment resulting from restriction digestion of $\mathrm{pUC} 19$ plasmid DNA (Fig. 7A). The resulting 1468 bp duplex contained $\sim 50$ labels, enabling a $1.2 \mathrm{pM}$ concentration of plasmid to be discriminated from the background due to unincorporated dUTP at a concentration of $10 \mathrm{nM}$ using burst counting in flow following a 200-fold dilution. This method has some potential drawbacks. The use of enzymatic labelling requires removal of any PCR inhibitors and introduces a potentially time consuming step; the duration of the extension reaction described was $1 \mathrm{~h}$, though it may be possible to reduce this. More fundamentally, the number of labels incorporated must be sufficient to outweigh the background, requiring relatively long products. One advantage that results from this is that spurious products due to primer-dimer formation should not produce sufficiently bright events to generate false-positives. Furthermore, reduction of the illuminated volume by confocal optics or the use of narrow nanofabricated channels would reduce the background and perhaps extend the sensitivity to shorter products.

A method described by Dubus et al. uses aromatic polymers to generate a large fluorescent signal upon hybridisation of capture oligonucleotides bound to magnetic microparticles (Fig. 7B). ${ }^{116}$ The cationic polythiophene binds both singleand double-stranded DNA, but undergoes a conformational change upon binding the latter, becoming strongly fluorescent (Fig. 7C). ${ }^{117}$ The capture beads were confined in a microfabricated electromagnetic trap for imaging, allowing detection of $11 \mathrm{aM}$ synthetic ssDNA.

\section{Co-localisation based detection}

As outlined in Fig. 3C, one popular implementation of SMFS involves using fluorophores attached to separate interacting biomolecules, leading to co-localisation of the dye molecules upon binding. When the chromophores are then simultaneously excited in the observation volume resulting from two overlapped laser beams, co-localisation gives rise to a simultaneous burst of emitted photons from both dyes, sometimes called a coincidence event (Fig. 8A). This approach has 


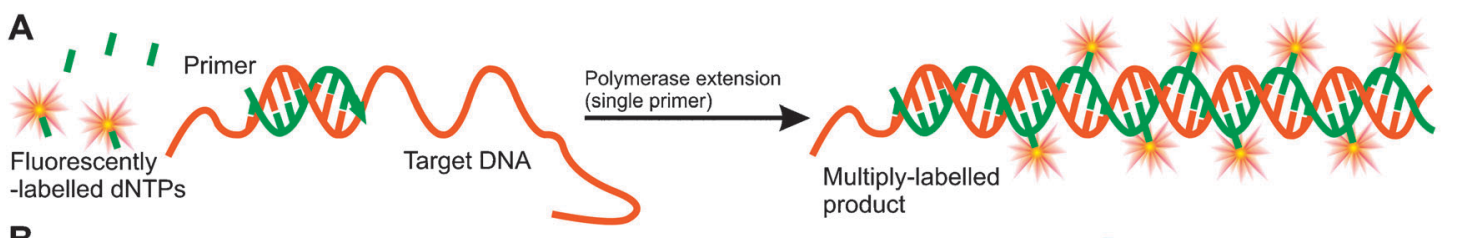

B
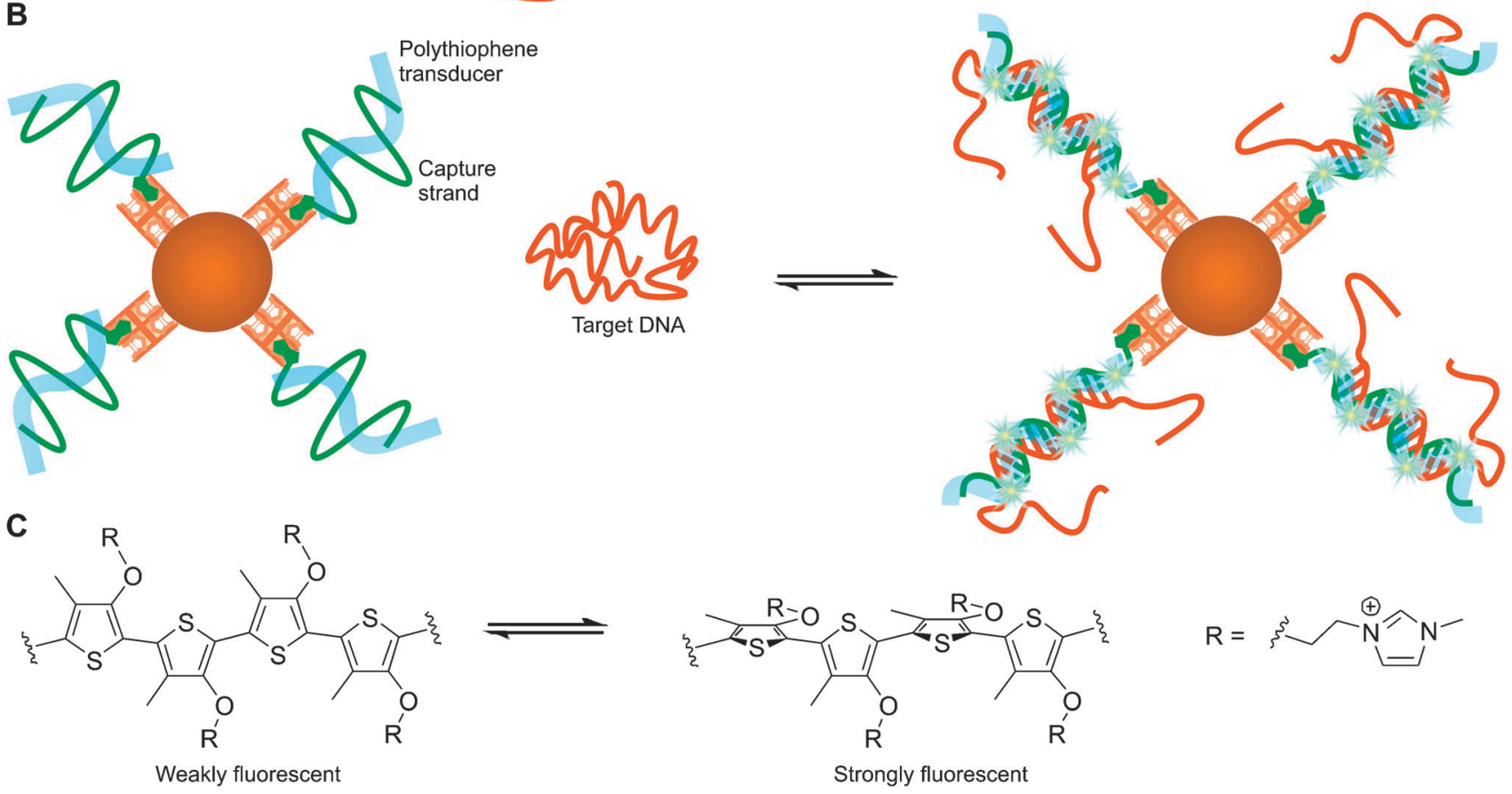

Fig. 7 (A) Detection of target DNA using enzymatic labelling with multiple fluorophores. (B) Generating a signal upon hybridisation of a bead-immobilised capture probe in the presence of a fluorescent polymer. (C) Conformations of imidazolium-derivatised polythiophene when bound to single-stranded (left) and double-stranded DNA (right).

advantages over the use of intensity alone for detection of nucleic acids, because background coincidence events are not caused by unconjugated dye molecules, unless there is a significant crosstalk between the two dyes (caused by 'leaking' of emission between detection channels), or if two dye molecules enter the excitation volume simultaneously, either by chance or non-specific association. Similarly, autofluorescent impurities are less likely to be detected in both channels.

The most convenient way of harnessing this technique for detection of non-fluorescent endogenous nucleic acids involves the use of two fluorescent probes which co-localise upon hybridisation to the same unlabelled target molecule, analogous to the 'sandwich' method used in immunoassays (Fig. 8B). This approach was first presented by Castro and Williams for amplification-free detection of genomic DNA, where phage $\lambda$ genomic DNA was detected using two $15 \mathrm{mer}$ peptide nucleic acid (PNA) probes, labelled with Rhodamine Green and BODIPY-TR, ${ }^{118}$ and later for detection of genomic DNA from Bacillus anthracis, the causative agent of anthrax. ${ }^{119}$ A similar assay has been used to probe gene expression using FCCS, where two labelled oligodeoxynucleotide probes were hybridised either to cDNA produced by reverse transcription, ${ }^{120}$ or directly to the mRNA. ${ }^{121}$

One disadvantage with homogenous 'sandwich'-hybridisation methods in the detection of unamplified genomic DNA arises because excess unhybridised fluorescent probes are not removed before analysis. As a result, the total concentration of fluorescent molecules must not exceed the single molecule regime $(\leq 250 \mathrm{pM})$, because the probability of chance coincidence events rises. ${ }^{122,123}$ However, it would be desirable for high concentrations of fluorescent probes to be used in the rapid detection of unamplified nucleic acids to accelerate rates of hybridisation. The problem of increased background signal in this scenario can be solved by the addition of an excess of complementary quencher-labelled oligonucleotides after target binding, to remove the signal from unhybridised probes (Fig. 8C). ${ }^{124}$ This approach was applied to the detection of $21 \mathrm{nt}$ microRNAs (miRNAs) using locked nucleic acid (LNA)/DNA mixmers. ${ }^{125}$ Another solution uses a pair of Molecular Beacons to bind the same target strand (Fig. 8D). ${ }^{126}$ This combination of intensity and co-localisation offers advantages over both separate methods; due to the efficient quenching in the 'closed' form, unbound probes are unlikely to give rise to coincident signals even if two (or more) unbound probes co-localise in the detection volume by chance.

Another issue with the co-localisation approach when using organic dyes as labels is that it is not possible to perfectly overlap tightly focussed laser beams of different colours in the $z$-direction, due to their different wavelengths. For example, the confocal volumes of the blue argon-ion $(488 \mathrm{~nm})$ and red $\mathrm{HeNe}(633 \mathrm{~nm})$ lasers can only be overlapped to $\sim 30 \%$ of the total volume, meaning that $70-80 \%$ of dual-labelled complexes only encounter one of the two excitation 

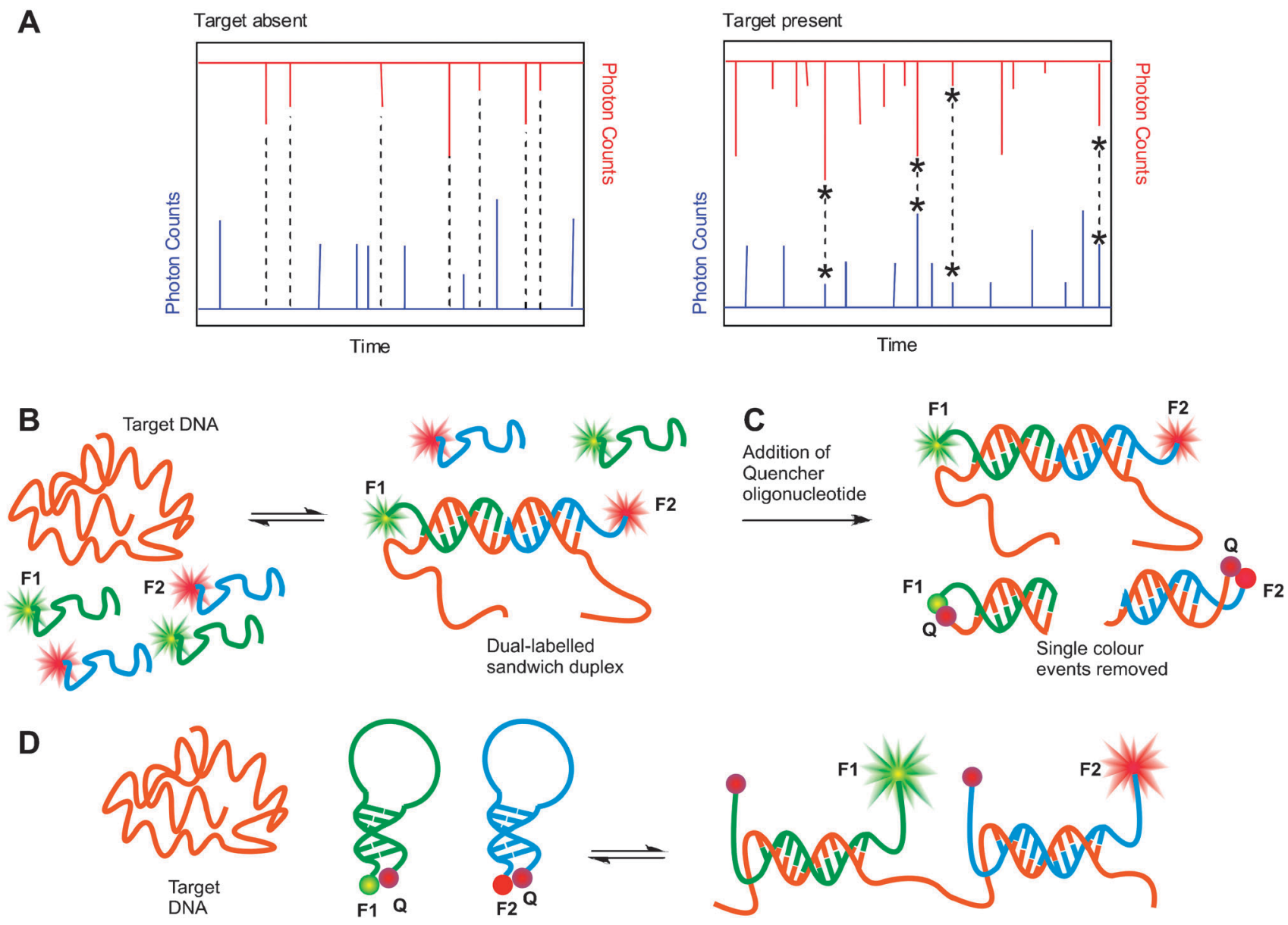

Fig. 8 (A) Co-localisation based detection of nucleic acid sequences. In the absence of the target sequence, bursts in each channel are uncorrelated. After probe binding, simultaneous bursts of fluorescence are observed in both channels $(*)$. (B) Generation of coincidence events by binding of two labelled oligonucleotides to unlabelled target DNA. (C) Removal of the background from unbound probes by hybridisation to complementary quencher strands after target binding. (D) Co-localisation of two fluorescently-labelled Molecular Beacons on a target.

wavelengths and therefore are not detected as coincidence events. $^{27}$ To improve the detection efficiency, pairs of fluorophores that can be excited at a common wavelength, but whose emission spectra are resolvable can be used, such as quantum dots, ${ }^{127}$ or organic dye-doped energy transfer polymeric nanoparticles (TransFluoSpheres). ${ }^{128}$ These brighter labels could also be detected by simplified wide-field imaging optical setups. ${ }^{129,130}$ Alternatively, a combination of quantum dot and organic labels can be used as a reporter system. ${ }^{131}$ In this example (Fig. 9), an Oregon Green-labelled probe is ligated to a biotinylated probe in a template-dependent reaction, followed by capture of the conjugate by multivalent streptavidin-coated QD 605 quantum dots $\left(\lambda_{\mathrm{em}}=605 \mathrm{~nm}\right)$. Although fewer coincident complexes are formed because multiple organic fluorophores are captured by each quantum dot, the resulting increased brightness of these species enables a higher threshold to be used, which enhances the discrimination from background chance co-localisation events.

\section{FRET-based detection}

The use of SMD also allows the study of individual FRET pairs (Fig. 3B). When a single donor is excited in sufficient proximity to a suitable acceptor, photons are emitted by the acceptor. If the FRET efficiency is less than $100 \%$, emission can be detected from both the donor and the acceptor (Fig. 10A), and coincidence analysis can be applied. ${ }^{132}$ Indeed, spFRET assays can be considered to be a subset of co-localisation methods in which the donor and acceptor are extremely close in space. In analytical assays for nucleic acids, there are advantages over both intensity-based and coincidence detection; the dependency of energy transfer on the inverse of the sixth power of the interfluorophore separation means that it is not enough for two dyes to occupy the detection volume simultaneously (diameter $\approx 1 \mu \mathrm{m}$ ) to generate a chance FRET signal, rather they must maintain a proximity in the nanometre range for a significant fraction of the measurement time. The probability of this occurring by chance is vanishingly small even at relatively high concentrations. Furthermore, as only one excitation wavelength is used, there is no loss of detection efficiency in confocal measurements due to imperfect overlap of laser sources, although the overlap of detection volumes defined by separate pinholes must still be optimised. However, direct excitation of the acceptor at donor's excitation wavelength and spectral crosstalk from donor emission can lead to weak signals in the 

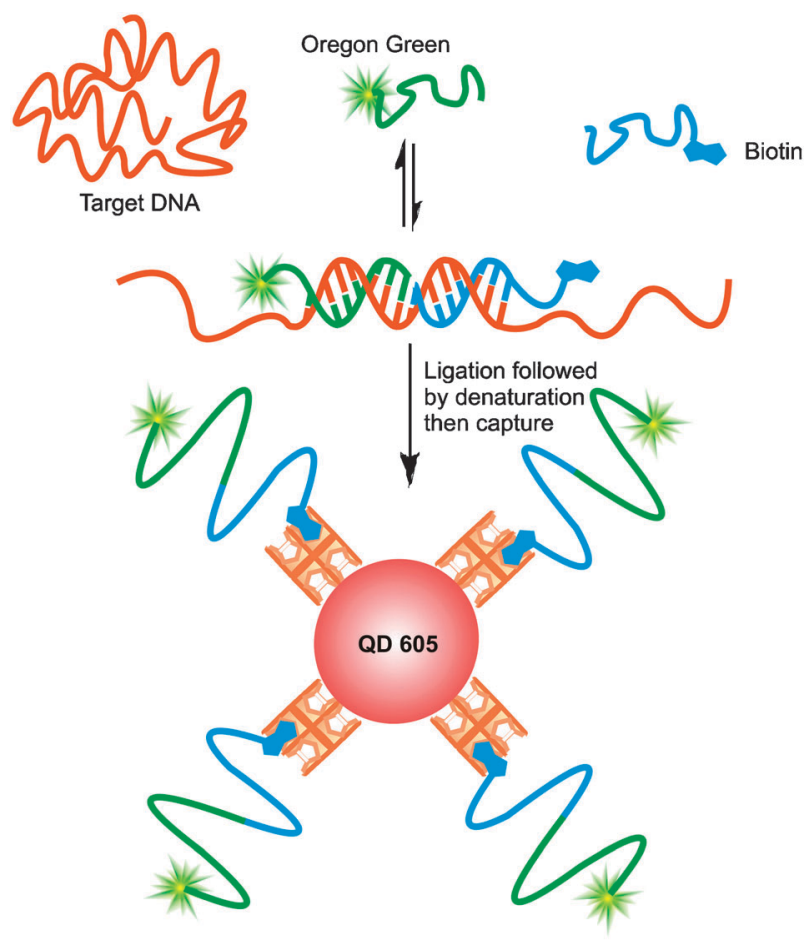

Fig. 9 Generation of dual-labelled species by target-dependent ligation of dye- and biotin-labelled probes followed by capture to a quantum dot.

acceptor emission channel. These possible sources of false positives have to be filtered out by thresholding.

An assay based on spFRET detection of a 'reverse Molecular Beacon' formed by target-dependent ligation of a pair of labelled oligonucleotides has been described by Wabuyele et $a l .{ }^{133}$ The two probes each contain a target-binding sequence and a $10 \mathrm{nt}$ arm sequence complementary to each other. These arm sequences do not hybridise to form an intermolecular duplex (due to its low thermodynamic stability), but following ligation and re-equilibration a conformational re-organisation into an intramolecular hairpinloop occurs, placing the donor (Cy5) in close proximity to the acceptor (Cy5.5), leading to FRET (Fig. 10B). The detection of a point mutation in the K-ras oncogene of 600 copies of human genomic DNA (corresponding to a concentration of $50 \mathrm{aM}$ ) was demonstrated, using a single ligation cycle (5 min duration) and spFRET measurement in electrokinetic flow.

Since a high degree of spectral overlap between donor emission and acceptor excitation is required for efficient FRET, the suppression of direct acceptor excitation requires a donor fluorophore with a large Stokes shift. Another disadvantage of spFRET detection is that the total signal from the acceptor will be lower than that obtained by excitation at its absorption maximum if the energy transfer is less than $100 \%$ efficient, which could make binding events difficult to resolve from the background fluorescence. The use of a multivalent quantum dot as a donor for multiple organic fluorophores could address both of these issues, and take advantage of the highly efficient energy transfer reported between quantum dots and organic dyes in flow. ${ }^{134}$ The assay developed by Zhang and co-workers (Fig. 10C) ${ }^{135}$ uses a streptavidin-functionalised quantum dot (QD605) as a FRET donor for Alexa Fluor 647. The excitation of the quantum dot at $488 \mathrm{~nm}$ elicits negligible emission from Alexa Fluor 647 $\left(\lambda_{\max }=650 \mathrm{~nm}\right)$, and the capture of $\sim 50$ acceptor duplexes per quantum dot ensures high acceptor fluorescence, enabling a high threshold to be used. Detection in pressure-driven flow allowed a limit of detection of $4.8 \mathrm{fM}$ unlabelled target DNA, a tenfold improvement over a Molecular Beacon assay in a head-to-head comparison. This concept has recently been extended to capture two target sequences on single quantum dots followed by detection using a combination of coincidence and FRET. ${ }^{136}$ Others have used quantum dots with fluorescent intercalators as FRET acceptors (Fig. 10D) such as ethidium, ${ }^{137}$ BOBO-3, ${ }^{138}$ or YOYO-3, ${ }^{139}$ which could simplify assay design.

\section{Future challenges}

This article has highlighted several assay formats that achieve ultrasensitive fluorescence-based detection of nucleic acids. The progress in this burgeoning field has been made possible by contributions from many fields, including single molecule spectroscopy, micro- and nanofabrication, chemistry of organic and inorganic labels, and nucleic acid synthesis. An important question remains though: what developments are still required to translate these promising research methods into real-world analytical applications? One important challenge lies in the integration of devices for sample preparation (e.g. cell lysis, nucleic acid extraction and purification), hybridisation and detection. Most of the assays described here rely on the use of pre-processed, purified DNA samples. Micro total analysis systems (' $\mu$ TAS'), in which several steps are carried out in one automated device, are one attractive solution, particularly for 'point-of-care' applications. In this setting, it is important that tests can be carried out by medical personnel without the need for significant additional training, which is a major driver for the development of 'sample-inanswer-out' instruments. $\mu$ TAS are already becoming established for detection of nucleic acids from biological samples, but the vast majority use PCR amplification. ${ }^{140}$ In fact, very few platforms that integrate sample preparation with single molecule detection have been reported so far. One notable exception demonstrated lysis of mammalian cells, specific antibody-labelling, analyte separation by electrophoresis, and finally SMFS in flow for detection of proteins from single cells, all in a single microfluidic chip. ${ }^{141}$ The development of such multifunctional devices for nucleic acid analysis will enable ultrasensitive tests to be practised outside of specialist research laboratories.

Another way that the utility of amplification-free genetic analysis could be extended is in the simultaneous detection of different DNA sequences, or multiplexing. Applications for this technology range from large scale expression analysis of hundreds or thousands of human genes to monitoring mutations in a few loci associated with cancer or detection of a small panel of pathogen-specific genomic sequences. Multiplexed analysis of amplified nucleic acids typically uses positionally-encoded microarrays, or microparticle-based assays, which may be encoded by many methods. ${ }^{142}$ Different 
A

Target absent

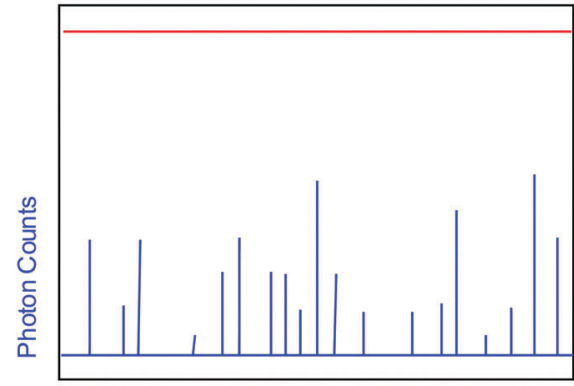

Time
Target present

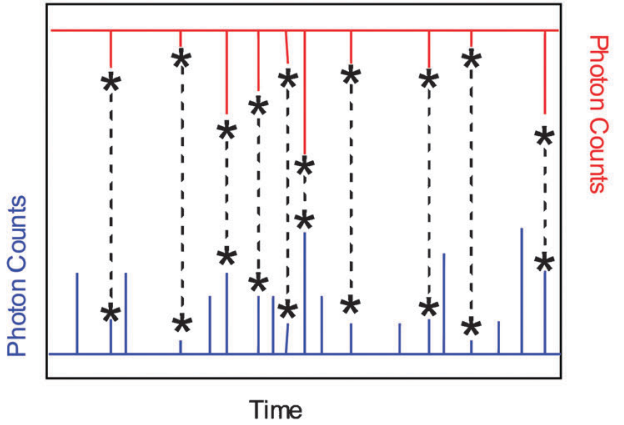

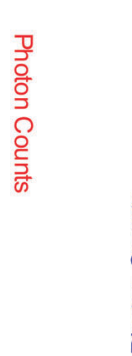

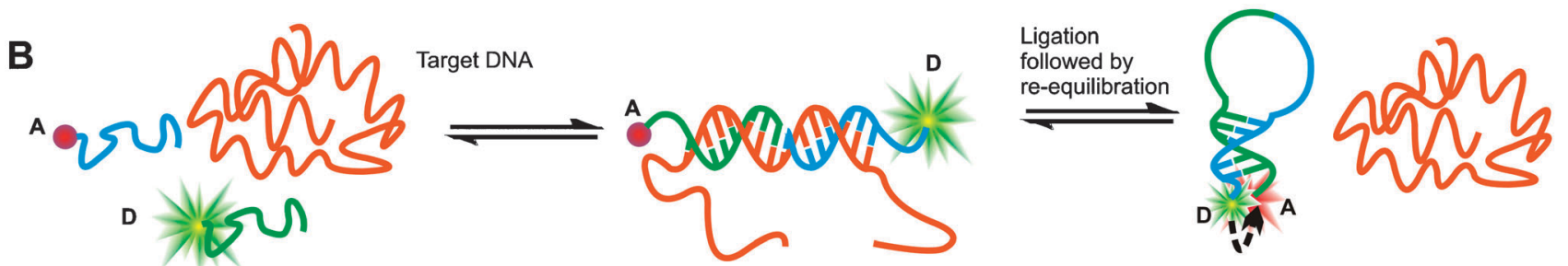

C
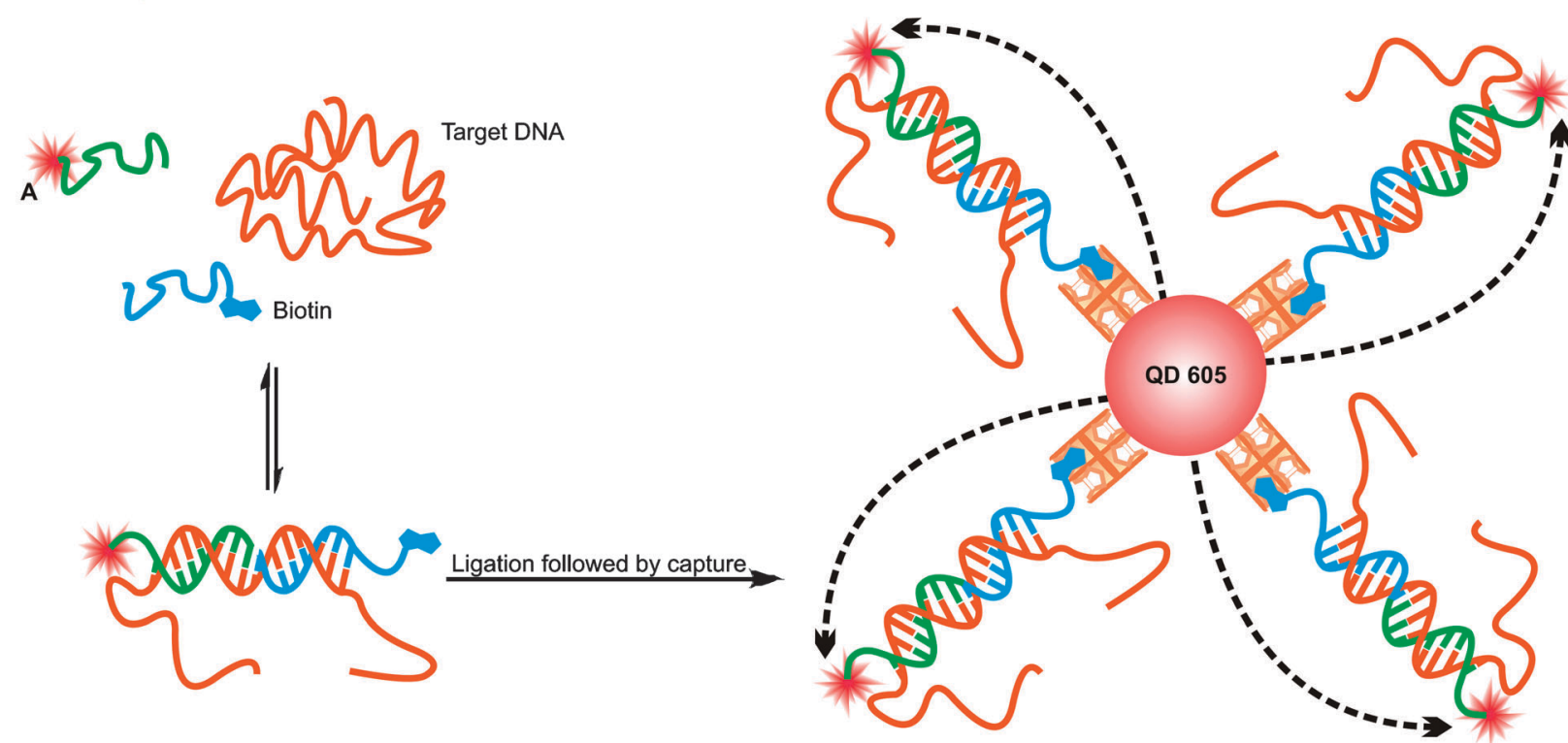

D
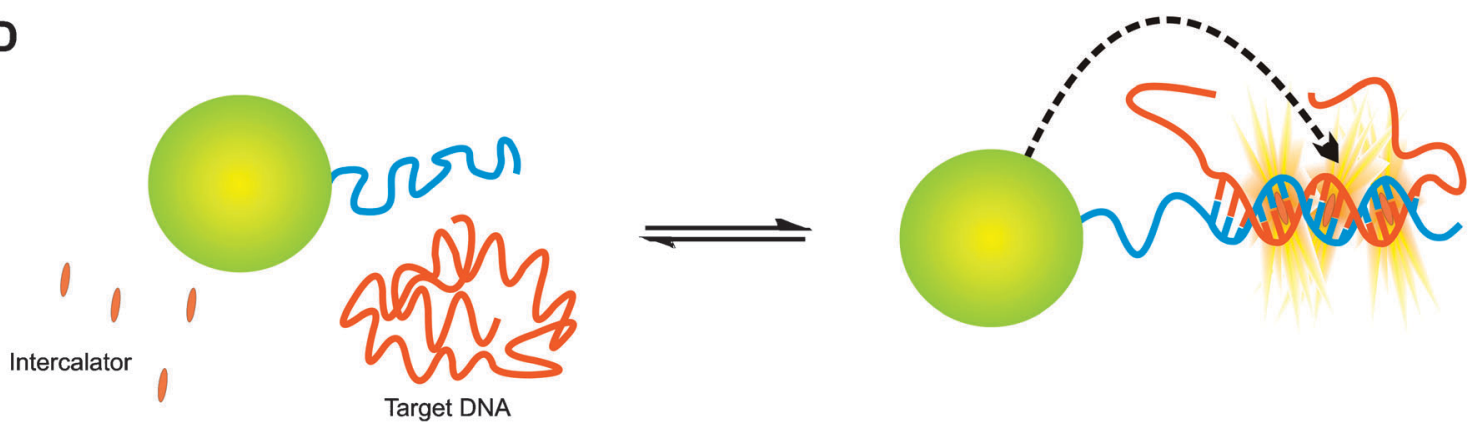

Fig. 10 (A) Idealised data from FRET-based detection. In the absence of the target, there are no acceptor signals. Upon hybridisation, excitation of the donor results in bursts of fluorescence from the donor and acceptor simultaneously (*). (B) Reverse Molecular Beacon strategy for detection by FRET. (C) Use of non-covalent capture to generate a FRET nanoassembly, with one quantum dot as a donor for multiple organic fluorophores. (D) Energy transfer between a quantum dot and fluorescent intercalators upon hybridisation.

strategies are required for coding single molecule assays; for example Ho et al. demonstrated detection of three different sequences using target-directed co-localisation of pairs of quantum dots with three different emission wavelengths. ${ }^{129}$ 
A 'Nanostring'.

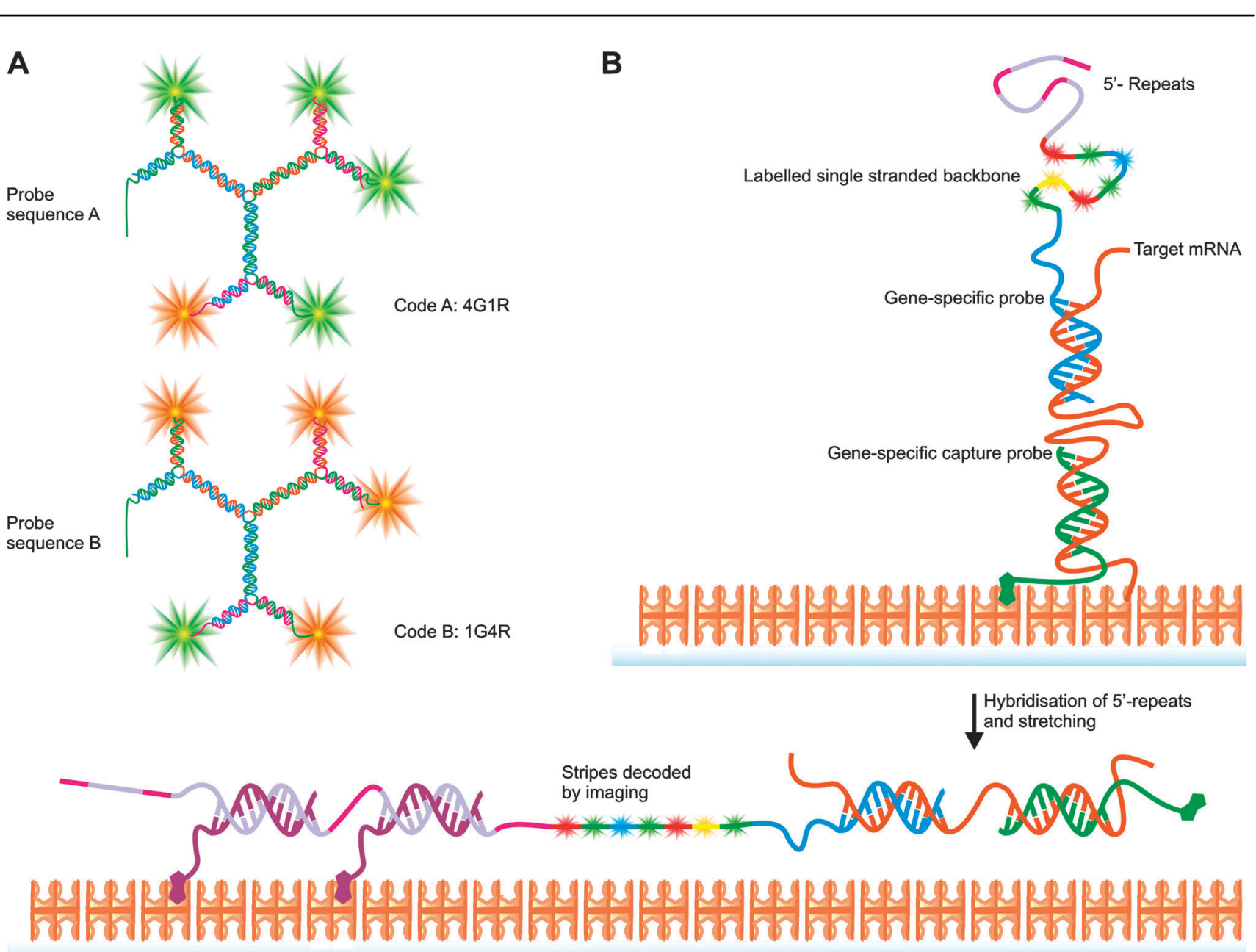

Fig. 11 Coding of single molecules. (A) Nanobarcodes made from dendrimer-like Y-shaped DNA. (B) Detection and coding of mRNAs using

This concept could be extended to higher order multiplexing by the use of more spectroscopically resolvable quantum dots; the use of ten resolvable emission colours as previously demonstrated $^{143}$ would generate 45 distinct coding pairs. Others have used DNA nanostructures with multiple fluorescent labels as barcodes. Dendrimer-like 'Y-shaped' and 'X-shaped' DNAs incorporating three- and four-way junctions (Fig. 11A) have been used as nanobarcodes for microsphere-based assays, ${ }^{143,144}$ though these could be adapted for use in the single molecule detection mode. The 'Nanostring' nCounter system uses long, multiply fluorescently-labelled sequences as coding and detection elements to assay single mRNA molecules. The target is sandwiched between the coded probe and a biotinylated capture sequence by hybridisation. After immobilisation to a surface, the coding sequence is stretched and aligned by an electric field, which enables counting and decoding of the resultant stripes of fluorescence by imaging (Fig. 11B). With seven coded 'bits' in one of four colours, an encoding capacity of 16384 is reached. This commercial system has allowed multiplexed detection of 509 human genes with a sensitivity of $0.1-0.5 \mathrm{fM} .^{145}$ Efforts to build new barcodes for single molecule assays should be greatly facilitated by the exciting recent developments in the assembly of nucleic acid nanostructures. ${ }^{146}$

\section{Acknowledgements}

The authors thank Dr Paul Dunne (University of Cambridge) for his critical reading of the manuscript. R.T.R. thanks the European Commission (FP7) for funding. T.B. has received funding from the European Union's Seventh Framework Programme (FP7/2007-2013) under grant agreement no 201418 (READNA).

\section{Notes and references}

1 The PCR Revolution: Basic Technologies and Applications, ed. S. A. Bustin, Cambridge University Press, Cambridge, UK, 2009.

2 H.-C. Yeh, S.-Y. Chao, Y.-P. Ho and T.-H. Wang, Curr. Pharm. Biotechnol., 2005, 6, 453.

3 D. R. Bentley, S. Balasubramanian, H. P. Swerdlow, G. P. Smith, J. Milton, C. G. Brown, K. P. Hall, D. J. Evers, C. L. Barnes, H. R. Bignell, J. M. Boutell, J. Bryant, R. J. Carter, R. K. Cheetham, A. J. Cox, D. J. Ellis, M. R. Flatbush, N. A. Gormley, S. J. Humphray, L. J. Irving, M. S. Karbelashvili, S. M. Kirk, H. Li, X. Liu, K. S. Maisinger, L. J. Murray, B. Obradovic, T. Ost, M. L. Parkinson, M. R. Pratt, I. M. J. Rasolonjatovo, M. T. Reed, R. Rigatti, C. Rodighiero, M. T. Ross, A. Sabot, S. V. Sankar, A. Scally, G. P. Schroth, M. E. Smith, V. P. Smith, A. Spiridou, P. E. Torrance, S. S. Tzonev, E. H. Vermaas, K. Walter, X. Wu, L. Zhang, M. D. Alam, C. Anastasi, I. C. Aniebo, 
D. M. D. Bailey, I. R. Bancarz, S. Banerjee, S. G. Barbour, P. A. Baybayan, V. A. Benoit, K. F. Benson, C. Bevis, P. J. Black, A. Boodhun, J. S. Brennan, J. A. Bridgham, R. C. Brown, A. A. Brown, D. H. Buermann, A. A. Bundu, J. C. Burrows, N. P. Carter, N. Castillo, M. C. E. Catenazzi, S. Chang, R. Neil Cooley, N. R. Crake, O. O. Dada, K. D. Diakoumakos, B. Dominguez-Fernandez, D. J. Earnshaw, U. C. Egbujor, D. W. Elmore, S. S. Etchin, M. R. Ewan, M. Fedurco, L. J. Fraser, K. V. F. Fajardo, W. S. Furey, D. George, K. J. Gietzen, C. P. Goddard, G. S. Golda, P. A. Granieri, D. E. Green, D. L. Gustafson, N. F. Hansen, K. Harnish, C. D. Haudenschild, N. I. Heyer, M. M. Hims, J. T. Ho, A. M. Horgan, K. Hoschler, S. Hurwitz, D. V. Ivanov, M. Q. Johnson, T. James, T. A. Huw Jones, G.-D. Kang, T. H. Kerelska, A. D. Kersey, I. Khrebtukova, A. P. Kindwall, Z. Kingsbury, P. I. Kokko-Gonzales, A. Kumar, M. A. Laurent, C. T. Lawley, S. E. Lee, X. Lee, A. K. Liao, J. A. Loch, M. Lok, S. Luo, R. M. Mammen, J. W. Martin, P. G. McCauley, P. McNitt, P. Mehta, K. W. Moon, J. W. Mullens, T. Newington, Z. Ning, B. Ling Ng, S. M. Novo, M. J. O’Neill, M. A. Osborne, A. Osnowski, O. Ostadan, L. L. Paraschos, L. Pickering, A. C. Pike, A. C. Pike, D. Chris Pinkard, D. P. Pliskin, J. Podhasky, V. J. Quijano, C. Raczy, V. H. Rae, S. R. Rawlings, A. C. Rodriguez, P. M. Roe, J. Rogers, M. C. R. Bacigalupo, N. Romanov, A. Romieu, R. K. Roth, N. J. Rourke, S. T. Ruediger, E. Rusman, R. M. Sanches-Kuiper, M. R. Schenker, J. M. Seoane, R. J. Shaw, M. K. Shiver, S. W. Short, N. L. Sizto, J. P. Sluis, M. A. Smith, J. E. S Sohna, E. J. Spence, K. Stevens, N. Sutton, L. Szajkowski, C. L. Tregidgo, G. Turcatti, S. Vandevondele, Y. Verhovsky, S. M. Virk, S. Wakelin, G. C. Walcott, J. Wang, G. J. Worsley, J. Yan, L. Yau, M. Zuerlein, J. Rogers, J. C. Mullikin, M. E. Hurles, N. J. McCooke, J. S. West, F. L. Oaks, P. L. Lundberg, D. Klenerman, R. Durbin and A. J. Smith, Nature, 2008, 456, 53.

4 J. Eid, A. Fehr, J. Gray, K. Luong, J. Lyle, G. Otto, P. Peluso, D. Rank, P. Baybayan, B. Bettman, A. Bibillo, K. Bjornson, B. Chaudhuri, F. Christians, R. Cicero, S. Clark, R. Dalal, A. Dewinter, J. Dixon, M. Foquet, A. Gaertner, P. Hardenbol, C. Heiner, K. Hester, D. Holden, G. Kearns, X. Kong, R. Kuse, Y. Lacroix, S. Lin, P. Lundquist, C. Ma, P. Marks, M. Maxham, D. Murphy, I. Park, T. Pham, M. Phillips, J. Roy, R. Sebra, G. Shen, J. Sorenson, A. Tomaney, K. Travers, M. Trulson, J. Vieceli, J. Wegener, D. Wu, A. Yang, D. Zaccarin, P. Zhao, F. Zhong, J. Korlach and S. Turner, Science, 2009, 323, 133.

5 J. Korlach, P. J. Marks, R. L. Cicero, J. J. Gray, D. L. Murphy, D. B. Roitman, T. T. Pham, G. A. Otto, M. Foquet and S. W. Turner, Proc. Natl. Acad. Sci. U. S. A., 2008, 105, 1176.

6 R. T. Ranasinghe and T. Brown, Chem. Commun., 2005, 5487.

7 T. G. Drummond, M. G. Hill and J. K. Barton, Nat. Biotechnol., 2003, 21, 1192.

8 N. L. Rosi and C. A. Mirkin, Chem. Rev., 2005, 105, 1547.

9 H. Lord and S. O. Kelley, J. Mater. Chem., 2009, 19, 3127.

10 T. Hirschfeld, Appl. Opt., 1976, 15, 2965.

11 E. B. Shera, N. K. Seitzinger, L. M. Davis, R. A. Keller and S. A. Soper, Chem. Phys. Lett., 1990, 174, 553.

12 S. Weiss, Science, 1999, 283, 1676.

13 W. P. Ambrose, P. M. Goodwin, J. H. Jett, A. Van Orden, J. H. Werner and R. A. Keller, Chem.Rev., 1999, 99, 2929.

14 H. Li, L. Ying, X. Ren, S. Balasubramanian and D. Klenerman, Biochem. Soc. Trans., 2004, 32, 753.

15 P. Tinnefeld and M. Sauer, Angew. Chem., Int. Ed., 2005, 44, 2642.

16 E. Haustein and P. Schwille, Curr. Opin. Struct. Biol., 2004, 14, 531.

17 P. V. Cornish and T. Ha, ACS Chem. Biol., 2007, 2, 53.

18 A. A. Deniz, S. Mukhopadhyay and E. A. Lemke, J. R. Soc. Interface, 2008, 5, 15.

19 M. B. Schneider and W. W. Webb, Appl. Opt., 1981, 20, 1382.

20 S. Nie, D. T. Chiu and R. N. Zare, Science, 1994, 266, 1018.

21 J. Widengren, V. Kudryavtsev, M. Antonik, S. Berger, M. Gerken and C. A. M. Seidel, Anal. Chem., 2006, 78, 2039.

22 D. Magde, E. Elson and W. Webb, Phys. Rev. Lett., 1972, 29, 705.

23 R. Shusterman, S. Alon, T. Gavrinyov and O. Krichevsky, Phys. Rev. Lett., 2004, 92, 048303.
24 M. Eigen and R. Rigler, Proc. Natl. Acad. Sci. U. S. A., 1994, 91, 5740 .

25 P. Schwille, F. J. Meyer-Almes and R. Rigler, Biophys. J., 1997, 72, 1878.

26 R. Rigler, Z. Földes-Papp, F. J. Meyer-Almes, C. Sammet, M. Völcker and A. Schnetz, J. Biotechnol., 1998, 63, 97.

$27 \mathrm{H}$. Li, L. Ying, J. J. Green, S. Balasubramanian and D. Klenerman, Anal. Chem., 2003, 75, 1664.

28 D. Axelrod, J. Cell Biol., 1981, 89, 141.

29 D. Axelrod, Methods Enzymol., 2003, 361, 1.

30 M. J. Levene, J. Korlach, S. W. Turner, M. Foquet, H. G. Craighead and W. W. Webb, Science, 2003, 299, 682.

31 J. Reiss, M. Krawczak, M. Schloesser, M. Wagner and D. N. Cooper, Nucleic Acids Res., 1990, 18, 973.

32 J. Peccoud and C. Jacob, Biophys. J., 1996, 71, 101.

33 N. E. Broude, L. Zhang, K. Woodward, D. Englert and C. R. Cantor, Proc. Natl. Acad. Sci. U. S. A., 2001, 98, 206.

34 A.-C. Syvänen, Nat. Genet., 2005, 37, S5.

35 S. Fredriksson, J. Banér, F. Dahl, A. Chu, H. Ji, K. Welch and R. W. Davis, Nucleic Acids Res., 2007, 35, e47.

36 G. Khan, H. O. Kangro, P. J. Coates and R. B. Heath, J. Clin. Pathol., 1991, 44, 360.

37 L. Eckhart, J. Bach, J. Ban and E. Tschachler, Biochem. Biophys. Res. Commun., 2000, 271, 726.

38 W. A. Al-Soud, L. J. Jönsson and P. Rådström, J. Clin. Microbiol., $2000,38,345$.

39 W. Al-Soud and P. Rådström, J. Clin. Microbiol., 2001, 39, 485.

$40 \mathrm{P}$. Rådström, R. Knutsson, P. Wolffs, M. Lövenklev and C. Löfström, Mol. Biotechnol., 2004, 26, 133.

41 C. T. Wittwer, M. G. Herrmann, A. A. Moss and R. P. Rasmussen, BioTechniques, 1997, 22, 130.

42 M. U. Kopp, A. J. De Mello and A. Manz, Science, 1998, 280, 1046.

43 Y. Schaerli, R. C. Wootton, T. Robinson, V. Stein, C. Dunsby, M. A. A. Neil, P. M. W. French, A. J. Demello, C. Abell and F. Hollfelder, Anal. Chem., 2009, 81, 302.

44 M. García-Closas, K. M. Egan, J. Abruzzo, P. A. Newcomb, L. Titus-Ernstoff, T. Franklin, P. K. Bender, J. C. Beck, L. Le Marchand, A. Lum, M. Alavanja, R. B. Hayes, J. Rutter, K. Buetow, L. A. Brinton and N. Rothman, Cancer Epidemiol., Biomarkers Prev., 2001, 10, 687.

45 G. M. Whitesides, Nature, 2006, 442, 368.

46 P. Yager, T. Edwards, E. Fu, K. Helton, K. Nelson, M. R. Tam and B. H. Weigl, Nature, 2006, 442, 412.

47 P. S. Dittrich and A. Manz, Anal. Bioanal. Chem., 2005, 382, 1771.

48 H. Craighead, Nature, 2006, 442, 387.

49 N. J. Dovichi, J. C. Martin, J. H. Jett, M. Trkula and R. A. Keller, Anal. Chem., 1984, 56, 348.

50 N. Dovichi, J. Martin, J. Jett and R. Keller, Science, 1983, 219, 845.

51 D. C. Nguyen, R. A. Keller, J. H. Jett and J. C. Martin, Anal. Chem., 1987, 59, 2158.

52 Y.-H. Lee, R. G. Maus, B. W. Smith and J. D. Winefordner, Anal. Chem., 1994, 66, 4142.

53 L.-Q. Li and L. M. Davis, Appl. Opt., 1995, 34, 3208.

54 T.-H. Wang, Y. Peng, C. Zhang, P. K. Wong and C.-M. Ho, J. Am. Chem. Soc., 2005, 127, 5354.

55 N. Lermer, M. D. Barnes, C.-Y. Kung, W. B. Whitten and J. M. Ramsey, Anal. Chem., 1997, 69, 2115.

56 T. D. Rane, C. M. Puleo, K. J. Liu, Y. Zhang, A. P. Lee and T. H. Wang, Lab Chip, 2010, 10, 161.

57 M. Foquet, J. Korlach, W. Zipfel, W. W. Webb and H. G. Craighead, Anal. Chem., 2002, 74, 1415.

58 M. Foquet, J. Korlach, W. R. Zipfel, W. W. Webb and H. G. Craighead, Anal. Chem., 2004, 76, 1618.

59 S. M. Stavis, J. B. Edel, K. T. Samiee and H. G. Craighead, Lab Chip, 2005, 5, 337.

60 K. J. Liu and T.-H. Wang, Biophys. J., 2008, 95, 2964.

61 S.-Y. Chao, Y.-P. Ho, V. J. Bailey and T.-H. Wang, J. Fluoresc., 2007, 17, 767.

62 P. I. Okagbare and S. A. Soper, Analyst, 2009, 134, 97.

63 E. A. Lemke, Y. Gambin, V. Vandelinder, E. M. Brustad, H.-W. Liu, P. G. Schultz, A. Groisman and A. A. Deniz, J. Am. Chem. Soc., 2009, 131, 13610. 
64 C. M. Puleo, H. C. Yeh, K. J. Liu and T. H. Wang, Lab Chip, $2008,8,822$

65 C. M. Puleo and T.-H. Wang, Lab Chip, 2009, 9, 1065.

66 L. D. Lavis and R. T. Raines, ACS Chem. Biol., 2008, 3, 142.

67 J. R. Grunwell, J. L. Glass, T. D. Lacoste, A. A. Deniz, D. S. Chemla and P. G. Schultz, J. Am. Chem. Soc., 2001, 123, 4295.

68 M. A. Osborne, S. Balasubramanian, W. S. Furey and D. Klenerman, J. Phys. Chem. B, 1998, 102, 3160.

69 A. H. El-Sagheer and T. Brown, Chem. Soc. Rev., 2010, 39, 1388.

70 W.-C. Sun, K. R. Gee, D. H. Klaubert and R. P. Haugland, J. Org. Chem., 1997, 62, 6469.

71 N. Panchuk-Voloshina, R. P. Haugland, J. Bishop-Stewart, M. K. Bhalgat, P. J. Millard, F. Mao, W. Y. Leung and R. P. Haugland, J. Histochem. Cytochem., 1999, 47, 1179.

72 M. H. Lyttle, T. G. Carter, D. J. Dick and R. M. Cook, J. Org. Chem., 2000, 65, 9033.

73 R. B. Mujumdar, L. A. Ernst, S. R. Mujumdar, C. J. Lewis and A. S. Waggoner, Bioconjugate Chem., 1993, 4, 105.

74 S. R. Mujumdar, R. B. Mujumdar, C. M. Grant and A. S. Waggoner, Bioconjugate Chem., 1996, 7, 356.

75 J. R. Unruh, G. Gokulrangan, G. S. Wilson and C. K. Johnson, Photochem. Photobiol., 2005, 81, 682.

76 R. Philip, A. Penzkofer, W. Bäumler, R. Szeimies and C. Abels, J. Photochem. Photobiol., A, 1996, 96, 137.

77 G. Vamosi, C. Gohlke and R. Clegg, Biophys. J., 1996, 71, 972.

78 S. S. White, H. Li, R. J. Marsh, J. D. Piper, N. D. Leonczek, N. Nicolaou, A. J. Bain, L. Ying and D. Klenerman, J. Am. Chem. Soc., 2006, 128, 11423.

79 J. E. Berlier, A. Rothe, G. Buller, J. Bradford, D. R. Gray, B. J. Filanoski, W. G. Telford, S. Yue, J. Liu, C.-Y. Cheung, W. Chang, J. D. Hirsch, J. M. Beechem, R. P. Haugland and R. P. Haugland, J. Histochem. Cytochem., 2003, 51, 1699.

80 M. J. Rust, M. Bates and X. Zhuang, Nat. Methods, 2006, 3, 793

81 M. Heilemann, S. van De Linde, A. Mukherjee and M. Sauer, Angew. Chem., Int. Ed., 2009, 48, 6903.

82 M. Cooper, A. Ebner, M. Briggs, M. Burrows, N. Gardner, R. Richardson and R. West, J. Fluoresc., 2004, 14, 145.

83 J. Vogelsang, S. Doose, M. Sauer and P. Tinnefeld, Anal. Chem., 2007, 79, 7367.

84 C. Eggeling, C. Ringemann, R. Medda, G. Schwarzmann, K. Sandhoff, S. Polyakova, V. N. Belov, B. Hein, C. von Middendorff, A. Schönle and S. W. Hell, Nature, 2008, 457, 1159.

85 A. Glazer and H. Rye, Nature, 1992, 359, 859.

86 A. Van Orden, R. A. Keller and W. P. Ambrose, Anal. Chem., 2000, 72, 37.

87 Y. Ma, M. R. Shortreed and E. S. Yeung, Anal. Chem., 2000, 72, 4640.

88 E. S. Yeung, Chem. Rec., 2001, 1, 123.

89 Y. Ma, M. R. Shortreed, H. Li, W. Huang and E. S. Yeung, Electrophoresis, 2001, 22, 421.

90 M. Bruchez, M. Moronne, P. Gin, S. Weiss and A. P. Alivisatos, Science, 1998, 281, 2013.

91 W. C. Chan and S. Nie, Science, 1998, 281, 2016.

92 M. Nirmal, B. O. Dabbousi, M. G. Bawendi, J. J. Macklin, J. K. Trautman, T. D. Harris and L. E. Brus, Nature, 1996, 383, 802.

93 U. Resch-Genger, M. Grabolle, S. Cavaliere-Jaricot, R. Nitschke and T. Nann, Nat. Methods, 2008, 5, 763.

94 I. L. Medintz, H. T. Uyeda, E. R. Goldman and H. Mattoussi, Nat. Mater., 2005, 4, 435.

95 W. R. Algar, A. J. Tavares and U. J. Krull, Anal. Chim. Acta, 2010, 673, 1

96 N. Kaji, M. Tokeshi and Y. Baba, Chem. Rec., 2007, 7, 295.

97 J. E. Whitaker, R. P. Haugland, D. Ryan, P. C. Hewitt, R. P. Haugland and F. G. Prendergast, Anal. Biochem., 1992, 207, 267.

98 R. F. Kubin and A. N. Fletcher, J. Lumin., 1983, 27, 455.

99 J. Tellinghuisen, P. M. Goodwln, W. P. Ambrose, J. C. Martin and R. A. Keiiert, Anal. Chem., 1994, 66, 64.

100 D. Magde, G. E. Rojas and P. G. Seybold, Photochem. Photobiol., 1999, 70, 737.

101 L. G. Lee, C. R. Connell and W. Bloch, Nucleic Acids Res., 1993, 21, 3761 .

102 N. Thelwell, S. Millington, A. Solinas, J. Booth and T. Brown, Nucleic Acids Res., 2000, 28, 3752.
103 I. A. Nazarenko, S. K. Bhatnagar and R. J. Hohman, Nucleic Acids Res., 1997, 25, 2516.

104 J. J. Li, Y. Chu, B. Y.-H. Lee and X. S. Xie, Nucleic Acids Res., 2008, 36, e36.

105 X. Zuo, F. Xia, Y. Xiao and K. W. Plaxco, J. Am. Chem. Soc., 2010, 132, 1816.

106 K. J. Liu, M. V. Brock, I.-M. Shih and T.-H. Wang, J. Am. Chem. Soc., 2010, 132, 5793.

107 S. Tyagi and F. R. Kramer, Nat. Biotechnol., 1996, 14, 303.

108 C.-Y. Zhang, S.-Y. Chao and T.-H. Wang, Analyst, 2005, 130, 483.

109 G. Bonnet, O. Krichevsky and A. Libchaber, Proc. Natl. Acad. Sci. U. S. A., 1998, 95, 8602.

110 C. A. M. Seidel, A. Schulz and M. H. M. Sauer, J. Phys. Chem., 1996, 100, 5541.

111 J. P. Knemeyer, N. Marmé and M. Sauer, Anal. Chem., 2000, 72, 3717.

112 N. Marmé, A. Friedrich, M. Müller, O. Nolte, J. Wolfrum, J. D. Hoheisel, M. Sauer and J.-P. Knemeyer, Nucleic Acids Res., 2006, 34, e90.

113 O. Piestert, H. Barsch, V. Buschmann, T. Heinlein, J.-P. Knemeyer, K. D. Weston and M. Sauer, Nano Lett., 2003, 3, 979.

114 N. R. Conley, A. K. Pomerantz, H. Wang, R. J. Twieg and W. E. Moerner, J. Phys. Chem. B, 2007, 111, 7929.

115 A. Castro, D. A. R. Dalvit and L. Paz-Matos, Anal. Chem., 2004, 76, 4169.

116 S. Dubus, J.-F. Gravel, B. Le Drogoff, P. Nobert, T. Veres and D. Boudreau, Anal. Chem., 2006, 78, 4457.

117 K. Doré, S. Dubus, H.-A. Ho, I. Lévesque, M. Brunette, G. Corbeil, M. Boissinot, G. Boivin, M. G. Bergeron, D. Boudreau and M. Leclerc, J. Am. Chem. Soc., 2004, 126, 4240.

118 A. Castro and J. G. K. Williams, Anal. Chem., 1997, 69, 3915.

119 A. Castro and R. T. Okinaka, Analyst, 2000, 125, 9.

120 A. Camacho, K. Korn, M. Damond, J. Cajot, E. Litborn, B. Liao, P. Thyberg, H. Winter, A. Honegger, P. Gardellin and R. Rigler, J. Biotechnol., 2004, 107, 107.

121 K. Korn, P. Gardellin, B. Liao, M. Amacker, A. Bergstrom, H. Bjorkman, A. Camacho, S. Dorhofer, K. Dorre, J. Enstrom, T. Ericson, T. Favez, M. Gosch, A. Honegger, S. Jaccoud, M. Lapczyna, E. Litborn, P. Thyberg, H. Winter and R. Rigler, Nucleic Acids Res., 2003, 31, 89e.

122 C. M. D’Antoni, M. Fuchs, J. L. Harris, H.-P. Ko, R. E. Meyer, M. E. Nadel, J. D. Randall, J. E. Rooke and E. A. Nalefski, Anal. Biochem., 2006, 352, 97.

123 A. Orte, R. Clarke, S. Balasubramanian and D. Klenerman, Anal. Chem., 2006, 78, 7707.

124 R. L. Nolan, H. Cai, J. P. Nolan and P. M. Goodwin, Anal. Chem., 2003, 75, 6236.

125 L. Neely, S. Patel, J. Garver, M. Gallo, M. Hackett, S. McLaughlin, M. Nadel, J. Harris, S. Gullans and J. Rooke, Nat. Methods, 2006, 3, 41.

126 Z. Földes-Papp, M. Kinjo, M. Tamura, E. Birch-Hirschfeld, U. Demel and G. P. Tilz, Exp. Mol. Pathol., 2005, 78, 177.

127 C.-Y. Zhang and L. W. Johnson, Analyst, 2006, 131, 484.

128 A. Agrawal, C. Zhang, T. Byassee, R. A. Tripp and S. Nie, Anal. Chem., 2006, 78, 1061.

129 Y.-P. Ho, M. C. Kung, S. Yang and T.-H. Wang, Nano Lett., $2005,5,1693$.

130 A. Agrawal, R. Deo, G. D. Wang, M. D. Wang and S. Nie, Proc. Natl. Acad. Sci. U. S. A., 2008, 105, 3298.

131 H.-C. Yeh, Y.-P. Ho, I.-M. Shih and T.-H. Wang, Nucleic Acids Res., 2006, 34, e35.

132 A. Orte, R. W. Clarke and D. Klenerman, Anal. Chem., 2008, 80, 8389.

133 M. B. Wabuyele, H. Farquar, W. Stryjewski, R. P. Hammer, S. A. Soper, Y.-W. Cheng and F. Barany, J. Am. Chem. Soc., 2003, 125, 6937.

134 C.-y. Zhang and L. W. Johnson, Angew. Chem., Int. Ed., 2007, 46, 3482 .

135 C.-Y. Zhang, H.-C. Yeh, M. T. Kuroki and T.-H. Wang, Nat. Mater., 2005, 4, 826.

136 C.-y. Zhang and J. Hu, Anal. Chem., 2010, 82, 1921.

137 D. Zhou, L. Ying, X. Hong, E. A. Hall, C. Abell and D. Klenerman, Langmuir, 2008, 24, 1659. 
138 T. C. Lim, V. J. Bailey, Y.-P. Ho and T.-H. Wang, Nanotechnology, 2008, 19, 075701.

139 D. Onoshima, N. Kaji, M. Tokeshi and Y. Baba, Anal. Sci., 2008, 24, 181.

140 L. Chen, A. Manz and P. J. R. Day, Lab Chip, 2007, 7, 1413.

141 B. Huang, H. Wu, D. Bhaya, A. Grossman, S. Granier, B. K. Kobilka and R. N. Zare, Science, 2007, 315, 81.

142 S. Birtwell and H. Morgan, Integr. Biol., 2009, 1, 345.

143 M. Han, X. Gao, J. Z. Su and S. Nie, Nat. Biotechnol., 2001, 19, 631.
144 J. B. Lee, Y. H. Roh, S. H. Um, H. Funabashi, W. Cheng, J. J. Cha, P. Kiatwuthinon, D. A. Muller and D. Luo, Nat. Nanotechnol., 2009, 4, 430.

145 G. K. Geiss, R. E. Bumgarner, B. Birditt, T. Dahl, N. Dowidar, D. L. Dunaway, H. P. Fell, S. Ferree, R. D. George, T. Grogan, J. J. James, M. Maysuria, J. D. Mitton, P. Oliveri, J. L. Osborn, T. Peng, A. L. Ratcliffe, P. J. Webster, E. H. Davidson, L. Hood and K. Dimitrov, Nat. Biotechnol., 2008, 26, 317.

146 J. B. Lee, M. J. Campolongo, J. S. Kahn, Y. H. Roh, M. R. Hartman and D. Luo, Nanoscale, 2010, 2, 188. 